\title{
Effect of Process Variables on the Inertia Friction Welding of Superalloys LSHR and Mar-M247
}

\author{
D.W. MAHAFFEY, O.N. SENKOV, R. SHIVPURI, and S.L. SEMIATIN
}

The effect of inertia friction welding process parameters on microstructure evolution, weld plane quality, and the tensile behavior of welds between dissimilar nickel-base superalloys was established. For this purpose, the fine-grain, powder metallurgy alloy LSHR was joined to coarse-grain cast Mar-M247 using a fixed level of initial kinetic energy, but different combinations of the flywheel moment of inertia and initial rotation speed. It was found that welds made with the largest moment of inertia resulted in a sound bond with the best microstructure and room-temperature tensile strength equal to or greater than that of the parent materials. A relationship between the moment of inertia and weld process efficiency was established. The post-weld tensile behavior was interpreted in the context of observed microstructure gradients and weld-line defects.

DOI: $10.1007 / \mathrm{s} 11661-016-3600-\mathrm{x}$

(C) The Minerals, Metals \& Materials Society and ASM International (outside the USA) 2016

\section{INTRODUCTION}

NiCKEL-BASE superalloys are widely used in aerospace applications involving elevated-temperature service but are generally considered difficult to weld. Nevertheless, a number of aerospace applications would benefit from hybrid (dual-/multi-alloy) structures comprising superalloys with dissimilar mechanical properties. For example, high-strength powder metallurgy (PM), or wrought superalloys are often beneficial in locations that require high strength levels at moderate temperatures. Likewise, heat-resistant, coarsegrain, or single-crystal cast superalloys are typically preferred in sections operating at higher temperatures or when creep resistance is critical. Several attempts have been made to join these types of dissimilar alloys using solid-state techniques such as friction welding. ${ }^{[1-4]}$ In friction welding methods, the materials are bonded in the solid state using friction-induced heating of the mating surfaces which are brought together by an applied compression force. By this means, solidification defects associated with fusion welding techniques are avoided. To produce a sound bond in practice, however, extensive plastic deformation and

D. W. MAHAFFEY, Materials Research Engineer, S.L. SEMIATIN, Senior Scientist, Materials Processing/Processing Science, are with the Air Force Research Laboratory, Materials and Manufacturing Directorate, AFRL/RXCM, Wright-Patterson Air Force Base, Dayton, OH 45433. Contact e-mail: David.Mahaffey.2@us.af.mil O.N. SENKOV, Senior Scientist, is with the Air Force Research Laboratory, Materials and Manufacturing Directorate, AFRL/RXCM, Wright-Patterson Air Force Base, and also with UES Inc., 4401 Dayton-Xenia Rd, Dayton, OH 45432

R. SHIVPURI, Professor of Integrated Systems Engineering, is with the College of Engineering, Ohio State University, Columbus, OH 43210.

D.W. Mahaffey and S.L. Semiatin are employed by the Air Force Research Laboratory, Materials and Manufacturing Directorate. U.S.

Government work is not protected by U.S. Copyright.

Manuscript submitted March 2, 2016.

Article published online June 8, 2016 mechanical mixing of the materials at the mating surfaces are required. ${ }^{[5]}$

In the specific process known as inertia friction welding (IFW), the energy is supplied by a rotating flywheel, and the primary process parameters are the flywheel moment of inertia (I), the initial flywheel rotation speed $\left(\omega_{0}\right)$, and the applied axial (forging) force $(P) . I$ and $\omega_{\mathrm{o}}$ define the initial kinetic energy of the flywheel $E_{\mathrm{ko}}$ (also referred to as the welding energy):

$$
E_{\mathrm{ko}}=\frac{I \omega_{\mathrm{o}}^{2}}{2} .
$$

During the IFW process, the kinetic energy of the flywheel is transformed into heat via friction at the weld interface. The energy required to produce a sound weld is generally considered a sufficient criterion for a given material combination and weld geometry. ${ }^{[6]}$ However, Eq. [1] indicates that numerous combinations of $I$ and $\omega_{\mathrm{o}}$ can produce the same value of $E_{\mathrm{ko}}$.

Recently, IFW was applied to join the forged, PM superalloy LSHR to coarse-grain, cast Mar-M247. ${ }^{[4]}$ The various welds exhibited two different types of mechanical behavior during post-weld tension testing ${ }^{[7]}$ : (1) plastic deformation and fracture on the Mar-M247 side outside the heat-affected zone (HAZ) or (2) fracture at the weld interface. For the latter failure mode, microstructural analysis revealed defects that weakened the weld interface. These flaws included submicron agglomerated/clustered oxide and carbide particles and/ or films at the weld interface and circumferential cracks at or near the interface on the Mar-M247 side. ${ }^{[4,7]}$ The carbide and oxide particles were deduced to have been produced by friction-induced milling of large carbide particles and oxide film(s), respectively. Furthermore, particle clustering was concluded to have resulted from insufficient radial plastic flow of Mar-M247 during IFW. This limited plastic flow inhibited "self-cleaning" at the weld interface and insufficient mechanical mixing 
of the mating surface layers (which tends to disperse undesirable inclusions into the bulk), both of which are characteristic of friction welding processes. The radial cracks at/near the weld interface were likely associated with insufficient workability of the weld material adjacent to the weld line which was forced to twist further immediately prior to cessation of flywheel rotation. In this regard, it was suggested that the propensity for the formation of radial cracks could be reduced if the flywheel rotation were stopped before the critical shear stress/strain for fracture at the bond line was reached.

One objective of the present work was to determine if the weld quality could be improved and defects suppressed during the IFW of dissimilar superalloys through the modification of one of the key process parameters, the moment of inertia of the flywheel, $I$. Another objective of this work was to determine if, given an appropriate forging force based on prior knowledge or experience, specifying the weld energy was sufficient to define appropriate welding parameters for a given set of materials. For this purpose, LSHR/ Mar-M247 welds were made using fixed values of $E_{\mathrm{ko}}$ and $P$, but $I$ and therefore $\omega_{\mathrm{o}}$ were varied. Such a variation would affect the degree as well as the duration of frictional heating at the interface and hence the nature of the plastic flow and fracture of the harderto-work material, Mar-M247.

\section{MATERIALS AND EXPERIMENTAL PROCEDURES}

The materials consisted of two nickel-base superalloys, isothermally forged LSHR (denoting "low-solvus, high refractory"), and investment cast Mar-M247, whose compositions are presented in Table I. The LSHR had an initial average gamma grain size of $3.5 \mu \mathrm{m}$. The total fraction of $\gamma^{\prime}$ particles was between 50 and 55 pct with primary $\gamma^{\prime}$ particles average size $\sim 1.3 \mu \mathrm{m}$ and secondary $\gamma^{\prime}$ particles average size $\sim 70$ to
$100 \mathrm{~nm}$. The microstructure of Mar-M247 comprised coarse grains that ranged between 1000 and $6000 \mu \mathrm{m}$ as well as cube-shaped $\gamma^{\prime}$ particles with $1.25 \mu \mathrm{m}$ average diameter ( $\sim 64$ pct volume fraction). The $\gamma^{\prime}$ solvus temperature of $\mathrm{LSHR}$ is $1430 \mathrm{~K}\left(1157^{\circ} \mathrm{C}\right)$; that of Mar-M247 is $1498 \mathrm{~K}\left(1225^{\circ} \mathrm{C}\right)$. The yield strength of LSHR is approximately 50 pct higher as that of Mar-M247 at temperatures to $1023 \mathrm{~K}\left(750{ }^{\circ} \mathrm{C}\right)$; at yet higher temperatures, Mar-M247 exhibits higher yield strength. ${ }^{[4,7]}$

LSHR samples measuring 12.7- $\mathrm{mm}$ diameter $\times$ 51-mm length were extracted from the center section of a 330-mm-diameter $\times$ 51-mm-thick pancake forging using electrical discharge machining (EDM). The longitudinal direction of the extracted samples was parallel to the short transverse direction of the pancake; the end surfaces of each sample coincided with the surfaces of the forging. Samples of Mar-M247 with the same dimensions were EDM'ed from an investment cast, 14.5-mm-thick, rectangular plate. The longitudinal direction of each Mar-M247 sample was parallel to the solidification direction. The EDM recast layer was removed by mechanical polishing.

Inertia friction welding trials were conducted to assess the effect of process parameters (Independent parameters labeled as Ind in Table II) on the weld output measures (dependent parameters labeled as Dep in Table II) as well as the quality of LSHR/Mar-M247 welds. The weld quality was determined from the mechanical test data of the samples in the as-welded form as well as a relative comparison of the weld-line defects present. The experiments consisted of clamping the LSHR sample to the flywheel, while the Mar-M247 sample was fixed in a non-rotating chuck connected to the hydraulic ram. After the pre-selected rotation speed/ energy was attained, the flywheel was decoupled from the motor and allowed to rotate freely while the mating surfaces of the LSHR and Mar-M247 were brought together. The axial compressive force was held constant until after the rotation stopped. For each of the trials

Table I. Average Composition (Wt Pet) of LSHR and Mar-M247 Program Materials

\begin{tabular}{lccccccccccccc}
\hline & $\mathrm{Al}$ & $\mathrm{B}$ & $\mathrm{C}$ & $\mathrm{Co}$ & $\mathrm{Cr}$ & $\mathrm{Hf}$ & $\mathrm{Mo}$ & $\mathrm{Nb}$ & $\mathrm{Ti}$ & $\mathrm{Ta}$ & $\mathrm{W}$ & $\mathrm{Zr}$ & $\mathrm{Ni}$ \\
\hline LSHR & 3.17 & 0.03 & 0.03 & 21.4 & 12.3 & 0.06 & 2.66 & 1.45 & 3.48 & 1.58 & 4.48 & 0.05 & 49.3 \\
Mar-M247 & 5.10 & - & 0.07 & 10.4 & 8.51 & 1.49 & 0.73 & 0.00 & 0.94 & 2.64 & 10.0 & 0.01 & 60.0 \\
\hline
\end{tabular}

Table II. Inertia Friction Welding Conditions

\begin{tabular}{lccccccc}
\hline Sample ID & $I\left(\mathrm{~kg} \mathrm{~m}^{2}\right)$ & $\omega_{\mathrm{o}}(\mathrm{rad} / \mathrm{s})$ & $E_{\mathrm{o}}(\mathrm{kJ})$ & $P(\mathrm{kN})$ & $\Delta l(\mathrm{~mm})$ & $T_{\mathrm{ss}}(\mathrm{N} \mathrm{m})$ & $\mu_{\mathrm{ss}}$ \\
\hline Parameter state & ind & ind & ind & ind & dep & dep & dep \\
LM01 & 0.166 & 518 & 22.3 & $60.0 \pm 1.5$ & 2.86 & $20.3 \pm 1.7$ & $0.074 \pm 0.006$ \\
LM02 & 0.381 & 340 & 22.0 & $60.0 \pm 1.5$ & 3.80 & $17.0 \pm 1.7$ & $0.064 \pm 0.006$ \\
LM03 & 0.802 & 235 & 22.1 & $60.0 \pm 1.5$ & 5.78 & $18.5 \pm 1.0$ & $0.069 \pm 0.004$ \\
\hline
\end{tabular}

$I$ flywheel moment of inertia, $\omega_{\mathrm{o}}$ initial rotation speed, $P$ axial compression load, $\Delta l$ total upset, $T_{\mathrm{ss}}$ steady-state total torque, $\mu_{\mathrm{ss}}$ apparent friction coefficient. 


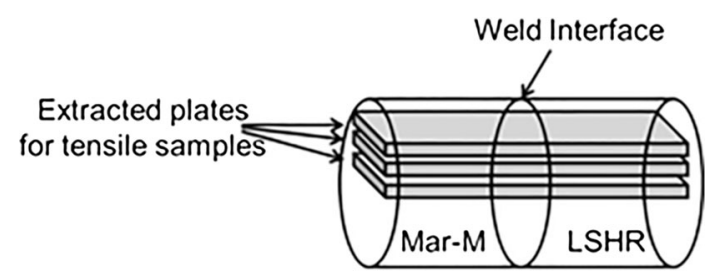

Fig. 1-Schematic illustration showing the locations of sub-scale tension samples relative to the weld interface.

(denoted as LM01, LM02, and LM03), the initial kinetic energy (Eq. [1]) was held constant at $22.0 \pm 0.3 \mathrm{~kJ}$, but the initial rotation speed, $\omega_{\mathrm{o}}$, and the moment of inertia, $I$, were varied accordingly. The axial load, $P$, pressing the weld surfaces together was approximately $60 \mathrm{kN}$ for each of the three welds. Slight differences in the initial rotation speed actual values as compared to the set-point values accounted for the small variation in kinetic energy of the welding trials $( \pm 0.3 \mathrm{~kJ})$. Temperature transients near the weld interface were monitored with thermocouples attached to the Mar-M247 samples at specified distances from the joint interface. The post-weld total lengths of the samples were measured via calipers after the welded samples cooled to room temperature. This value was subtracted from the combined initial length of the weld samples to determine the experimental upset length.

The welded samples were sectioned longitudinally, and the microstructure, defects, phases, chemical composition, and hardness were determined as a function of axial location relative to the weld interface. In particular, energy-dispersive spectroscopy (EDS), backscatter electron (BSE) imaging, and electron backscatter diffraction (EBSD) were performed in a scanning electron microscope (SEM) for microstructure and phase-composition analyses. Electron probe microanalysis (EPMA) was used to determine concentration profiles as a function of distance from the weld interface. To accomplish this task, longitudinal EPMA scans at various radial locations were conducted perpendicular to the weld interface to a distance of $300 \mu \mathrm{m}$ into each alloy using a spacing of $1 \mu \mathrm{m}$. Beyond $300 \mu \mathrm{m}$, the spacing was increased to $100 \mu \mathrm{m}$. Hardness measurements were conducted in a microhardness testing machine using a Vickers (diamond pyramid) indenter and a $500 \mathrm{~g}$ load held for 20 seconds.

To establish post-weld mechanical properties, three sub-scale tension specimens were excised via EDM from samples produced with each set of welding conditions. The samples were extracted at three radial locations relative to the central axis, $0.7,2.5$, and $4.3 \mathrm{~mm}$ (Figure 1). In all cases, the tension axis was parallel to the longitudinal axis of the welded bars, and the weld interface was located in the middle of the reduced (gage) section. Following EDM, the lateral surfaces of each tension sample were ground using 600-grit silicon carbide paper. Fiducial marks having a spacing of $1 \mathrm{~mm}$ and covering $26 \mathrm{~mm}$ in total length were laser inscribed on the reduced section. Tension testing was conducted at room temperature using a constant ram speed of $0.02 \mathrm{~mm} / \mathrm{s}$, which corresponded to an initial strain rate of $10^{-3} \mathrm{~s}^{-1}$. A differential image correlation technique was used to capture the development of strain non-uniformity within each of the inscribed sections during the tension tests. Details of this procedure were reported previously. ${ }^{[7]}$

A 2-D axisymmetric finite element model of the IFW process using the DEFORM ${ }^{\mathrm{TM}}$ software was utilized to explore the effect of the weld process parameters (including process efficiency) on weld upset and peak interface temperature. Trends in predicted upset and peak interface temperature from the computer simulations were compared to experimental results to aid in the interpretation and analysis of the welding process.

\section{RESULTS}

The principal results from this investigation consisted of quantitative measurements of the various process parameters, the evolution of macrostructure and microstructure, and post-welding mechanical properties.

\section{A. Inertia Friction Welding Process Measurements}

The rotation velocity, instantaneous kinetic energy, torque, duration, upset, and temperature transients varied noticeably for the different IFW trials. Due to friction between the mating surfaces of the weld samples as well as the rotating parts of the welding machine itself, the rotation velocity, $\omega$, and kinetic energy of the flywheel, $E_{\mathrm{k}}$, decreased continuously with time until the rotation stopped (Figure 2). The rate of change in rotational velocity, $a=-\mathrm{d} \omega / \mathrm{d} t$ (deceleration), was inversely proportional to $I$ (Figure 3(a)). In addition, an increase in $I$ from 0.166 to $0.802 \mathrm{~kg} \mathrm{~m}^{2}$ resulted in an approximate doubling of the duration of welding (i.e., $\sim 4$ to $\sim 9$ seconds) (Figure 2). For each trial, regardless of the value of $I$, the deceleration decreased as the processing time increased until minimum values were reached; then, at the very end of the process, when extensive sticking of the friction surfaces occurred, the deceleration rapidly increased until the IFW process stopped (Figure 3(a)).

The corresponding total torque $T$ (=sum of the torque $T_{\mathrm{S}}$ due to friction between the mating weld faces and the torque $T_{\mathrm{M}}$ due to friction in the bearings of the IFW machine), which is associated with the deceleration of the flywheel, and the apparent friction coefficient $\mu$, were determined using the following relations: ${ }^{[4]}$

$$
\begin{gathered}
T=I a, \\
\mu=1.5 T /\left(\operatorname{Pr}_{\mathrm{o}}\right),
\end{gathered}
$$

Here, $r_{\mathrm{o}}$ is the outer radius of the contacting surfaces of the cylindrical samples. In the present experiments, both $P$ and $r_{\mathrm{o}}$ can be considered constant. Therefore, $\mu$ is linearly proportional to $T$ and exhibits a similar 


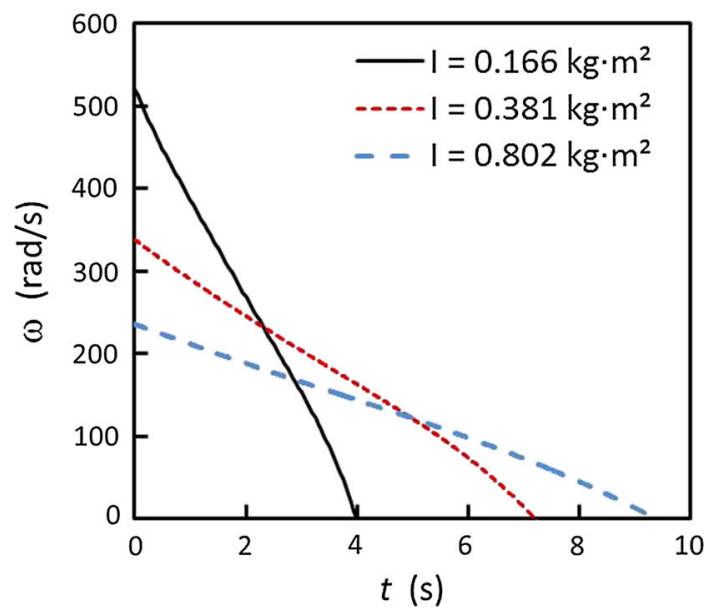

(a)

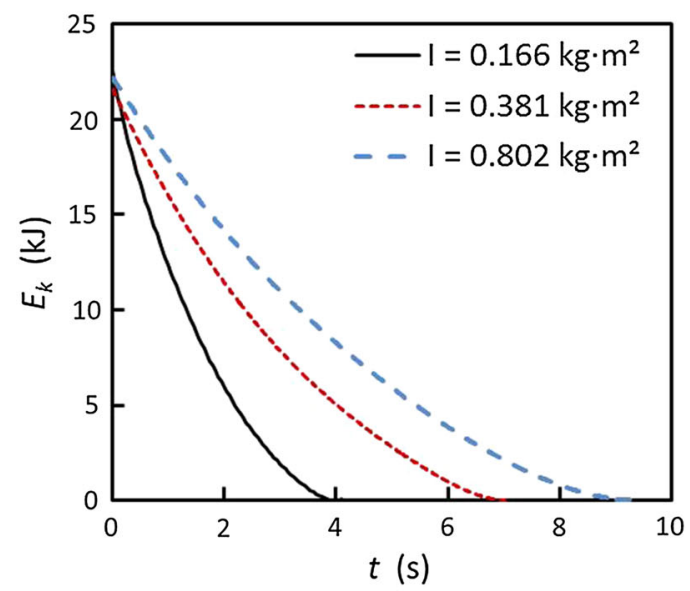

(b)

Fig. 2-Time dependence of $(a)$ the rotation speed, $\omega$, and $(b)$ kinetic energy, $E_{\mathrm{k}}$, of the flywheel for different values of the flywheel moment of inertia, I (Table II).

dependence on processing time $t$. Specifically, during each trial, $T$ decreased slightly, reached a minimum value at approximately two-thirds of the total duration of the IFW process, and then increased continuously, approaching a maximum value at the end (Figure 3(c)). In contrast to the deceleration behavior (Figures 3(a), (b)), the total torque exhibited a rather weak dependence on $I$ (Figures 3(c), (d)). The dependence of the total torque on $\omega$ during the initial steady-state stage (during which $T$ decreased at a constant rate with $\omega$ ) was nearly identical for different values of $I$ and can be described by the following relationship:

$$
T_{\mathrm{ss}}=T_{\mathrm{o}}(1+\tau \omega) .
$$

Here, $T_{\mathrm{ss}}$ is the total torque during the steady-state stage, and $T_{\mathrm{o}}$ and $\tau$ are $\omega$-independent parameters, which were determined from a linear fit (fine dotted line in Figure 3(d)) to be $T_{\mathrm{o}}=13 \pm 1 \mathrm{Nm}$, and $\tau=$ $1.5 \times 10^{-3}$ seconds. The average values of $T_{\mathrm{ss}}$ and friction coefficient $\mu_{\mathrm{ss}}$ varied from 17.0 to $20.5 \mathrm{Nm}$ and from 0.064 to 0.074 , respectively (Table II).

The length of upset during the experimental welding trials increased with an increase in the flywheel moment of inertia (Table II). The experimental upset length increased $\sim 2$ times with a $\sim 5$ times increase in moment of inertia.

The predicted upset was also shown to increase with an increase in moment of inertia (Figure 5(b)): the upset nearly doubled in magnitude for welds performed from $I=0.166$, to $0.802 \mathrm{~kg} \mathrm{~m}^{2}$. The actual upset from the experimental IFW trials exhibited a similar trend, ranging from 2.86 to $5.78 \mathrm{~mm}$ for $I=0.166$ and $0.802 \mathrm{~kg} \mathrm{~m}^{2}$, respectively (Table II).

Temperature transients measured on the Mar-M247 side at axial distances $L$ between $\sim 2.5$ and $7 \mathrm{~mm}$ from the weld interface revealed a striking dependence on the flywheel moment of inertia (Figure 4). Although the temperature increased at nearly the same rate for all three welds (at $L=4.7 \mathrm{~mm}$ ), the peak temperature increased with moment of inertia (Figure 4(a)). Furthermore, the peak temperature decreased nearly linearly with an increase in the axial distance from the weld interface (Figure 4(b)).

Temperature transients for the weld interface at the radial centerline $(L=r=0 \mathrm{~mm})$ predicted from DEFORM simulations showed an increasing heating rate to the peak temperature with a decrease in moment of inertia followed by a region of nearly steady-state behavior for the three welding conditions (Figure 5(a)). As the moment of inertia increased, the duration of the nearly steady-state temperature increased, while the predicted maximum temperatures decreased slightly.

\section{B. Metal Flow, Macrostructure, and Microstructure Observations}

The rate and duration of the energy input strongly affected metal flow behavior and the evolution of macrostructure and microstructure in the weld zone. For example, the shape and size of the zone of highly localized deformation at the weld line changed noticeably as a function of energy input rate (Figure 6). Due to the differences in flow behavior at elevated temperatures between the two alloys, most of the deformation during the weld process took place on the LSHR side. Sample LM01, which was welded with the smallest moment of inertia, shortest weld duration, and highest initial rotation speed, exhibited the smallest upset on both LSHR and Mar-M sides. The thickness of the radially deformed region (extending beyond the original diameter) was $\sim 1.1 \mathrm{~mm}$ and $2.2 \mathrm{~mm}$ on the LSHR and Mar-M247 sides, respectively (Figure 6(a)). Sample LM02 exhibited an intermediate degree of upset during welding. This upset was mainly due to extensive plastic deformation and material flow within $\sim 1.6 \mathrm{~mm}$ region near the weld interface on the LSHR side. The Mar-M247 side of LM02 exhibited limited plasticity, similar to that observed in sample LM01, with a slight barreling at the weld line. The thickness of the deformed region of LM02 was $\sim 2.2 \mathrm{~mm}$ (Figure 6(b)). Sample 


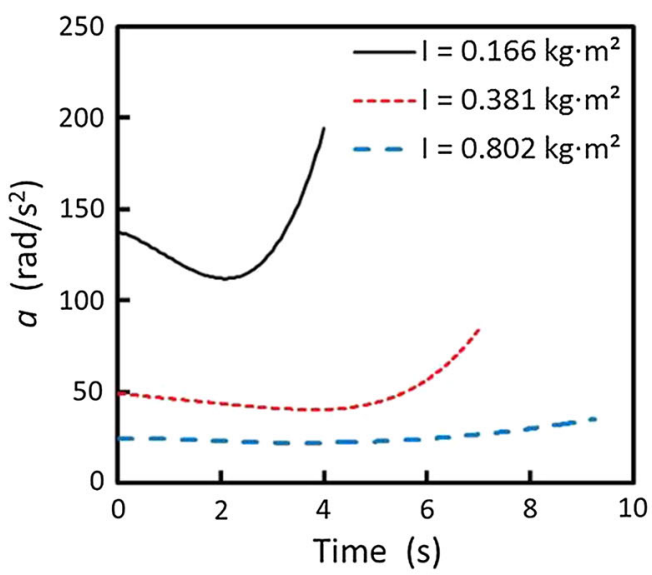

(a)

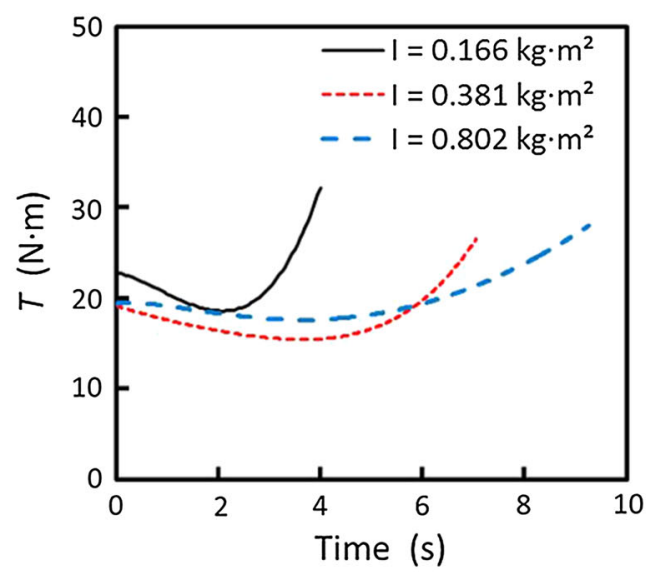

(c)

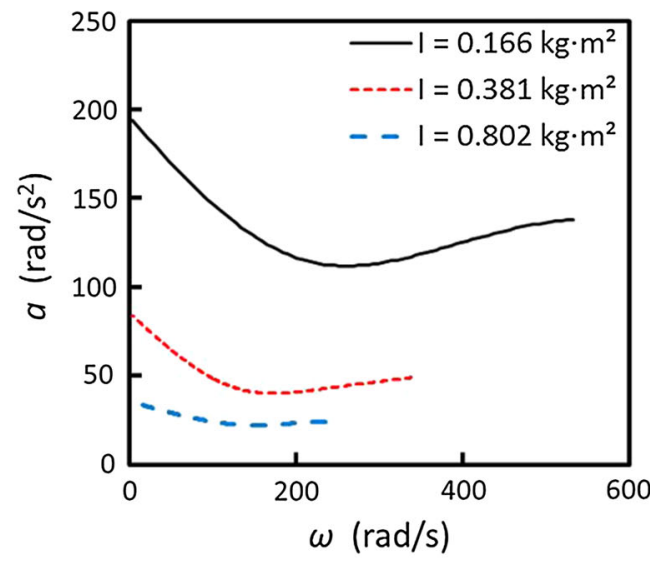

(b)

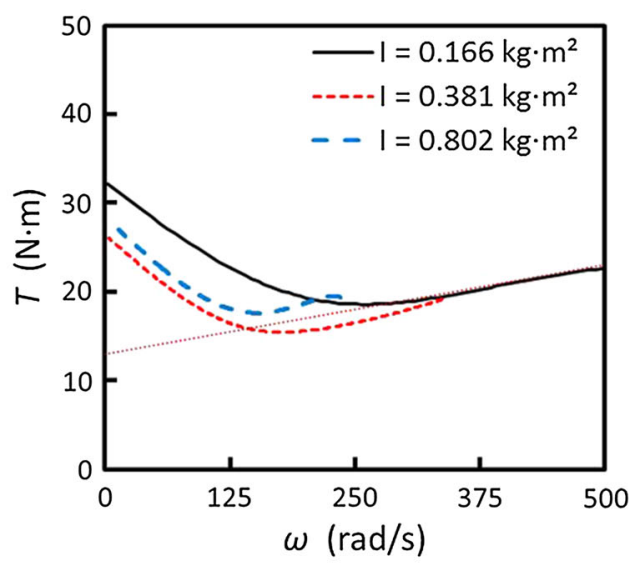

(d)

Fig. 3-Dependence of $(a, b)$ the flywheel deceleration, $a=-\mathrm{d} \omega / \mathrm{d} t$, and $(c, d)$ total friction torque, $T$, on $(a, c)$ the processing time and (b, d) rotation speed at different flywheel moments of inertia, I (Table II). The red dotted trend line in (d) corresponds to Eq. [4] (Color figure online).

LM03, which was welded using the highest $I$ and lowest $\omega_{\mathrm{o}}$, revealed the largest upset of the three welds with flash formation on the LSHR side and significant barreling of the Mar-M247 (Figure 6(c)). The thickness of the highly deformed region on the LSHR side was $\sim 1.4 \mathrm{~mm}$ and on the Mar-M247 side was $\sim 3.2 \mathrm{~mm}$.

The metal flow observations (Figure 6) also revealed that the weld lines in samples LM01 and LM02 were predominantly linear, while sample LM03 exhibited non-linear morphology. This is an important finding in that straight/flat weld interfaces in these materials often indicate a lack of plastic deformation, are usually decorated with fine carbide and oxide particles, and typically yield poor bond quality. ${ }^{[4,7]}$ It is also important to note that all three of the welds had the same applied axial load and initial flywheel kinetic energy, thus indicating that bond quality depended primarily on the flywheel moment of inertia and its impact on the weld duration. This observation is intuitive in that the weld times are longer, and therefore, the weld interface is held at an elevated temperature longer with a larger moment of inertia. By this means, frictional heat is able to conduct further axially (and radially) into the material, thereby increasing the volume of the plastically deformed region.
More-detailed examination of the weld line revealed a range of location-dependent characteristics which varied with welding conditions. For example, in sample LM01, well-welded regions with fine recrystallized $\gamma$ grains and no (or very few) welding defects (Figure 7(a)) occupied less than 30 pct of the weld interface area and were mainly observed in the mid-radius regions. Typical welding defects in LM01 were submicron carbide/oxide particles or films which decorated the weld interface area (Figures 7(b), (c)) and cracks along the weld interface (Figure 7(d)). These defects were present at all radial locations. A tabular description of bond-line defects encountered in the three welds is contained in Table III.

The weld quality of sample LM02 was better. More than 70 pct of the weld interface contained no welding defects (Figures 8(a), (b)). Typical welding defects at the bond line in LM02 were carbide films, carbide and oxide particles (Figure 8(c)), and radial cracks (Figure 8(d)). These defects were observed mainly in the outer diameter (OD) regions. The carbides that decorated the linear regions of the weld line appeared as continuous films or stringers, which tended to have a smooth surface adjacent to the LSHR side, and a lobed surface that protruded into the Mar-M247 (Figure 8(c)). This observation may be indicative of bond-line temperatures 


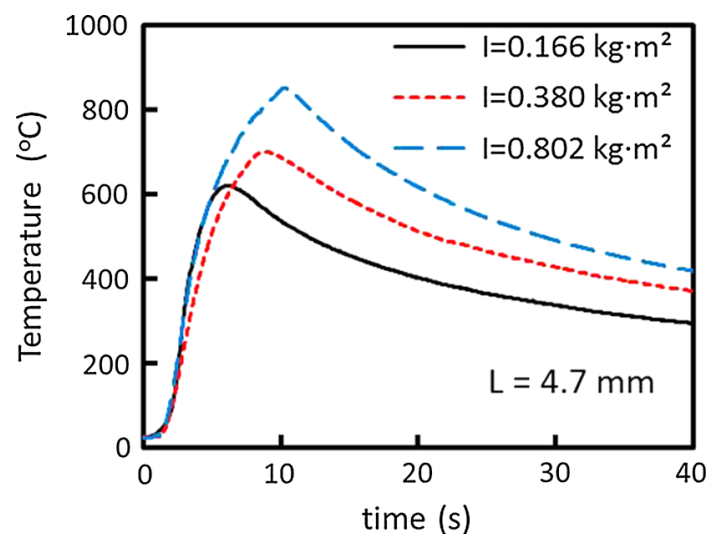

(a)

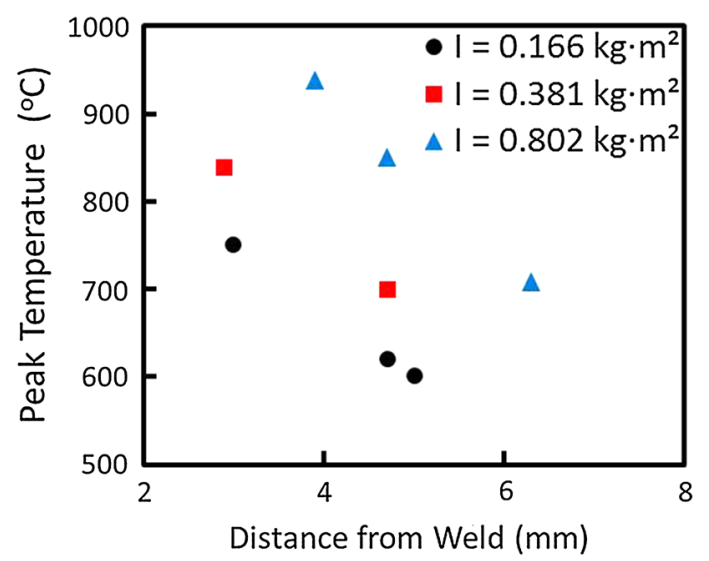

(b)

Fig. 4-(a) Temperature versus time transients measured within Mar-M247 at a distance $L=4.7 \mathrm{~mm}$ from the interface during welding with three different flywheel moments of inertia. (b) Peak temperatures recorded within Mar-M247 at different distances from the weld interface during welding with three different flywheel moments of inertia.

during welding that were high enough to partially dissolve the carbides in the parent materials and then re-precipitate carbide films upon cooling.

Sample LM03, which exhibited the largest upset of the three welds with flash formation on the LSHR side and significant barreling of the Mar-M247 (Figure 6), exhibited a weld interface that was largely free of defects and had been extensively hot worked during IFW (Figures 9(c), (d)). Metal flow at the OD (Figure 9(d)) highlighted the development in LSHR of secondary flash as well as a thin ribbon that remained bonded to the Mar-M247 flash. Both the high degree of weld interface non-linearity and the absence of oxide and carbide particles at the interface indicated that the bond quality of sample LM03 was likely better than those of LM01 and LM02.

EBSD inverse pole figure (IPF) maps (for the tangential direction of each sample) determined at and near the weld line showed that the degree of recrystallization of the initially coarse-grain Mar-M247 was proportional to the moment of inertia (Figure 10). Specifically, the IPF map for the Mar-M247 material welded using the

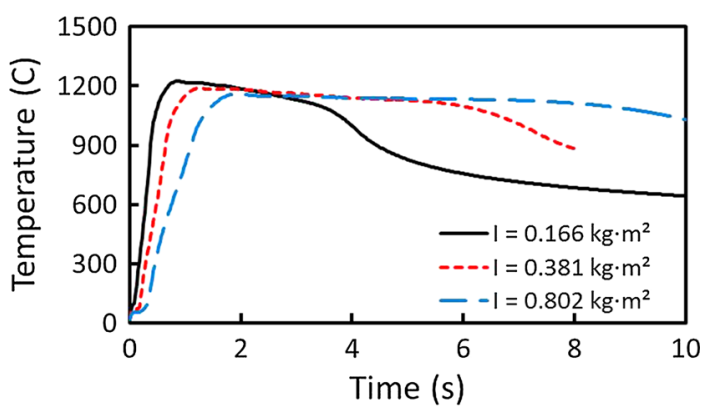

(a)

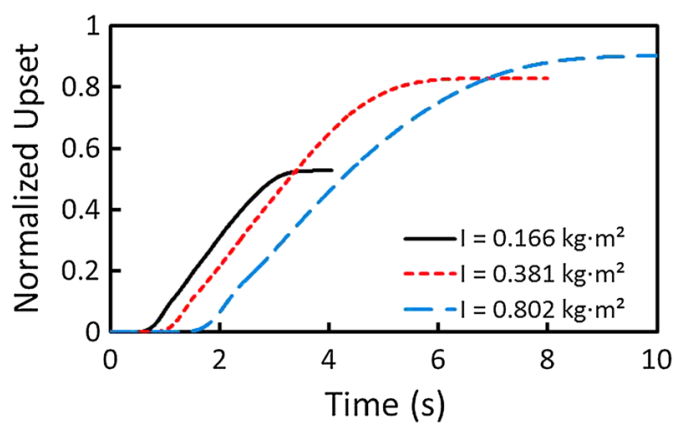

(b)

Fig. 5-FEM predictions of (a) temperature transients at the weld interface centerline location and $(b)$ upset behavior for three weld conditions in which the total energy was held constant and the efficiency varied according to the moment of inertia.

flywheel with the smallest moment of inertia (sample LM01) showed only slight color variation within the large grains near the weld line. This slight color variation and lack of associated fine-grain regions indicated minimal deformation and limited recrystallization (Figure 10(a)). With an increase in $I$, the degree of deformation of the large grains (indicated by color variations within the remnant grains) and the amount of recrystallization increased (Figure 10(b)). For the sample welded with the flywheel with the largest moment of inertia (LM03), the large grains were fragmented into smaller grains which contained necklace-like recrystallization along the boundaries (Figure 10(c)). The LSHR material also exhibited different behaviors depending on the flywheel moment of inertia. In particular, the degree of recrystallization increased significantly with increasing $I$. This behavior can be attributed to the fact that with an increase in moment of inertia, higher hot-working temperatures and longer weld durations were attained. This resulted in accommodation of more of the imposed deformation by LSHR.

\section{Chemical Mixing and Interdiffusion During IFW}

A comparison of the baseline composition of the program alloys (Table I) indicated that Mar-M247 has higher levels of $\mathrm{Ni}(60.3$ vs. $49.4 \mathrm{pct})$ and $\mathrm{W}$ (10.1 vs $4.3 \mathrm{pct})$ and a lower amount of Co (10.4 vs $21.4 \mathrm{pct})$ relative to LSHR. Friction-induced heating and extensive plastic deformation during IFW would thus be expected to bring about interdiffusion and mechanical 


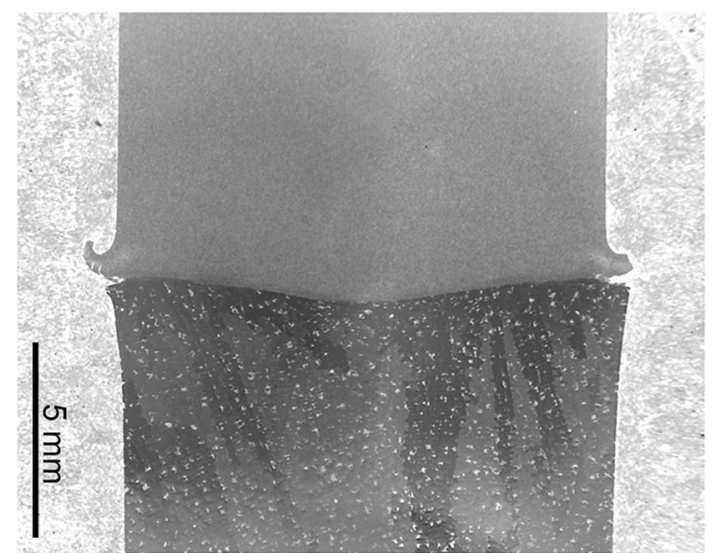

(a)

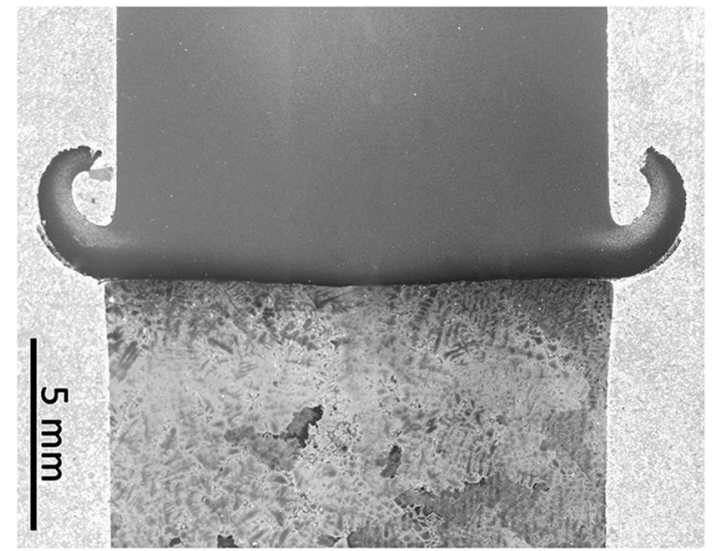

(b)

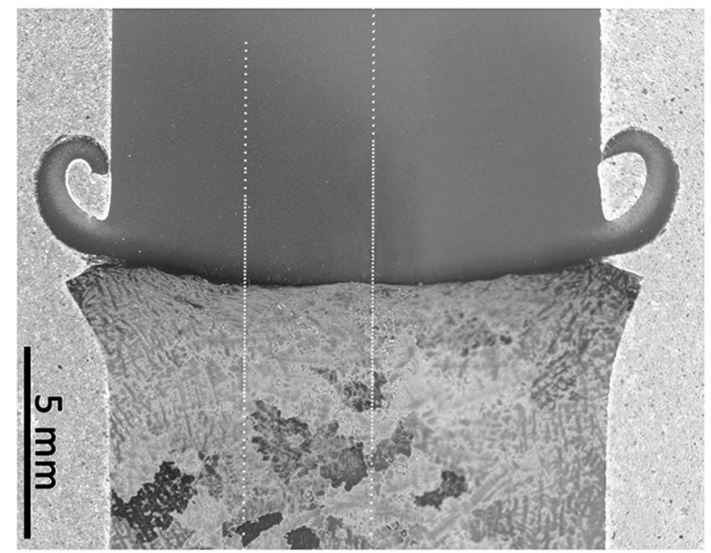

(c)

Fig. 6-Macrographs of etched IFW Mar-M247/LSHR weld cross sections highlighting changes in morphology of the narrow bands of localized deformation at the weld interface. LSHR is on the top and Mar-M247 is on the bottom of each macrograph.

mixing of these alloying elements and the formation of a transition zone with an intermediate composition. Experimental results in terms of EPMA composition profiles across the weld line at two different radial positions [center $(r=0)$ and $\mathrm{OD}(r=4.2 \mathrm{~mm})]$ quantified these phenomena (Figure 11). In these figures, the weld interface was taken to be the position at which the
BSE contrast changed sharply from lighter/higher $\mathrm{Z}$ (Mar-M247) to darker/lower Z (LSHR) (Figure 9).

The thickness of the transition zone from the Mar-M247 to the LSHR composition depended on processing conditions, radial position, and the thickness of the heavily deformed Mar-M247 layer near the interface. For example, at the center $(r=0)$ of samples LM01, LM02, and LM03 (the latter containing the heavily deformed layer on the Mar-M side of the interface), the thickness of this transition zone was similar, i.e., $16 \pm 2,15 \pm 2$, and $13 \pm 2 \mu \mathrm{m}$, respectively (Figures 11(a), (c), (e)). In this region, the composition of Mar-M247 started to change inside the fine-grain layer, $\sim 5$ to $7 \mu \mathrm{m}$ from the weld interface for LM01 and LM02 and $\sim 10 \mu \mathrm{m}$ for LM03. The composition of LSHR showed a more abrupt change within $\sim 9$ to $10 \mu \mathrm{m}$ from the weld interface for LM01 and LM02 and only $\sim 3 \mu \mathrm{m}$ for LM03.

At $r=4.2 \mathrm{~mm}$ (OD), no fine-grain layer was present on the Mar-M247 side of either LM01 or LM02, and the weld interface was contaminated with oxide and carbide particles. Here, the transition from the Mar-M247 to LSHR compositions occurred entirely on the LSHR side, and the thickness of the transition zone increased with an increase in the moment of inertia (i.e., an increase in welding time), viz., $15 \pm 2 \mu \mathrm{m}$ for LM01 (Figure 11(b)) and $29 \pm 2 \mu \mathrm{m}$ for LM02 (Figure 11(d)). In contrast with LM01 and LM02, sample LM03 exhibited a continuous fine-grain layer from the center to the OD on the Mar-M247 side of the weld interface, and this layer was wider at the OD than that in the center. The transition from the Mar-M247 to the LSHR composition at the OD of sample LM03 occurred mainly inside the fine-grain region. The thickness of the transition zone inside the fine-grain Mar-M247 side was estimated to be $\sim 50 \mu \mathrm{m}$, and only $\sim 4 \mu \mathrm{m}$ on the LSHR side (Figure 11(f)). These observations suggested that LSHR was softer during trials LM01 and LM02, deformed more severely than Mar-M247, and thus experienced more extensive mechanical mixing into Mar-M247. Enhanced (pipe) diffusion associated with the finer grain size and associated increased grain boundary length of LSHR may also have contributed to the formation of the transition zone on the LSHR side. By similar reasoning, the deep transition zone in LM03 on the Mar-M247 side and a thinner zone on the LSHR side, relative to the LM01 and LM02 samples, can be associated with heavier deformation in Mar-M247, and a higher degree of mechanical mixing of the two alloys during IFW.

The EPMA data also revealed extensive scatter about the average concentration values in both Mar-M247 and LSHR far from the weld interface (Figure 11). This scatter arose mainly from the presence of large primary (or secondary) $\gamma^{\prime}$ precipitates having higher $\mathrm{Ni}$ and lower Co than the $\gamma$ matrix. Carbide particles enriched in $\mathrm{Ta}$, Hf, $\mathrm{Ti}$, and/or $\mathrm{W}$ and depleted in $\mathrm{Ni}$ also contributed to the scatter in the data; the position of these minor-phase particles can be correlated to locations which exhibited a considerable drop in Ni. In LSHR near the IFW interface, the composition scatter associated with the $\gamma^{\prime}$ phase was noticeably lower. The 


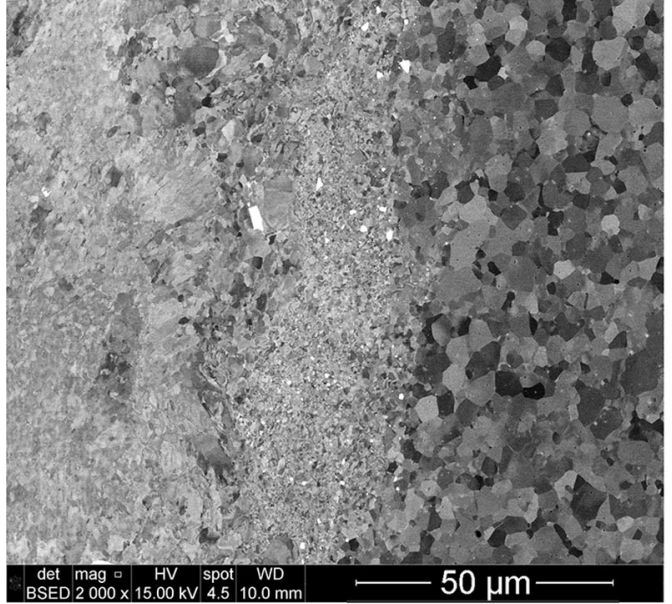

(a)

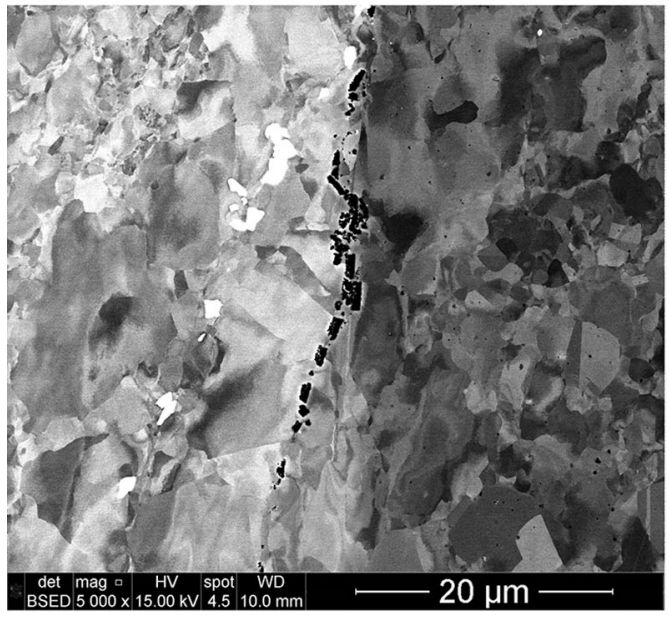

(c)

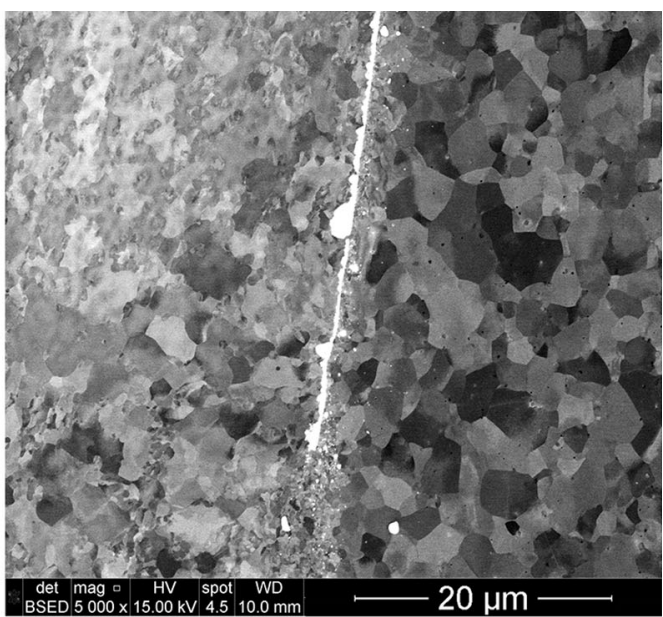

(b)

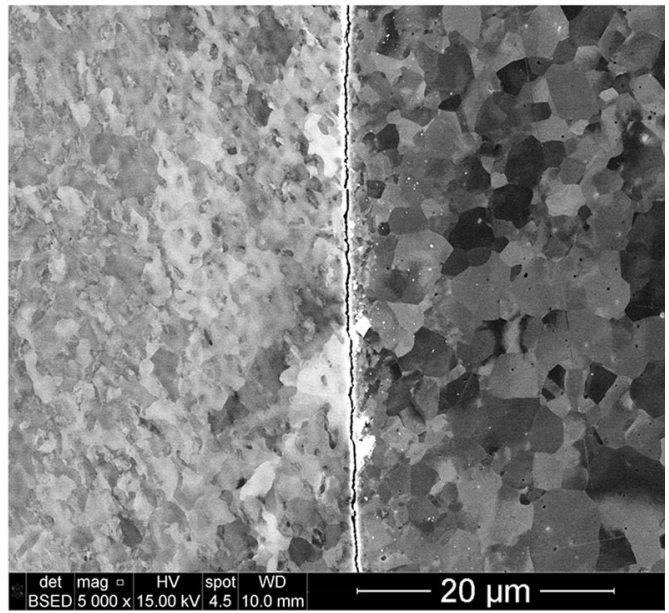

(d)

Fig. 7-SEM backscattered electron images of weld sample LM01 showing different regions of the weld interface (Mar-M247 is on the left, and LSHR is on the right of each image): (a) A defect-free, dynamically recrystallized layer at the weld interface in the mid-radius region, (b) a weld-line region with agglomerated submicron-size carbide particles, $(c)$ a chain of oxide particles, and $(d)$ a crack at the weld interface.

Table III. Incidence of Defect Occurrence at the Weld Line

\begin{tabular}{llll}
\hline Sample ID & Oxide/Carbide Precipitates & Linear Bond-line & Porosity/Cracks \\
\hline LM01 & high & medium & low \\
$r=0.7 \mathrm{~mm}$ & high & medium & high \\
$r=2.5 \mathrm{~mm}$ & low & medium & low \\
$r=4.3 \mathrm{~mm}$ & - & - & - \\
$\mathrm{LM} 02$ & low & low & low \\
$r=0.7 \mathrm{~mm}$ & high & high & \\
$r=2.5 \mathrm{~mm}$ & - & - & - \\
$r=4.3 \mathrm{~mm}$ & - & - & - \\
$\mathrm{LM} 03$ & - & - & - \\
$r=0.7 \mathrm{~mm}$ & - & & \\
$r=2.5 \mathrm{~mm}$ & & & \\
\hline
\end{tabular}

formation of this homogeneous region likely resulted from dynamic dissolution of large primary (and secondary) $\gamma^{\prime}$ particles during IFW and subsequent re-precipitation of finer $\gamma^{\prime}$ during rapid cooling upon completion of the weld..$^{[4,8,9]}$ The thickness of the homogeneous region tended to increase with radial distance from the center and a decrease in the flywheel moment of inertia. For example, near the center of LM01, LM02, and LM03, the homogenized regions were $\sim 50,33$, and $22 \mu \mathrm{m}$, while at the $\mathrm{OD}$, these regions increased to 135,114 , and $105 \mu \mathrm{m}$, respectively (Figure 11). 


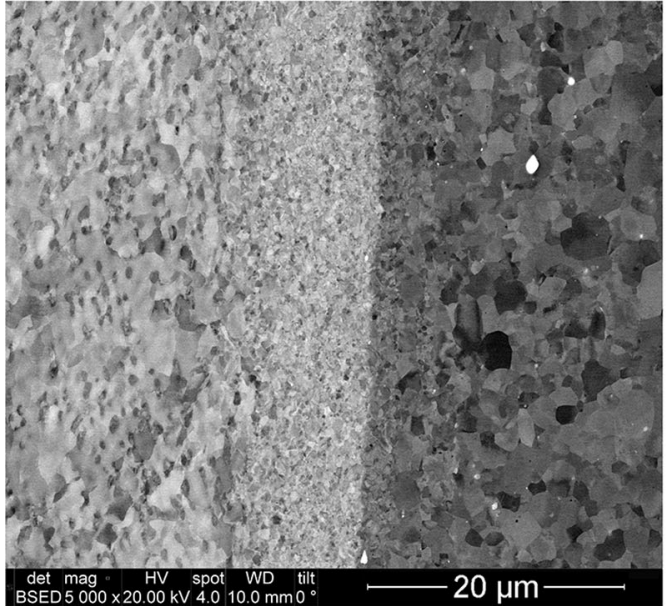

(a)

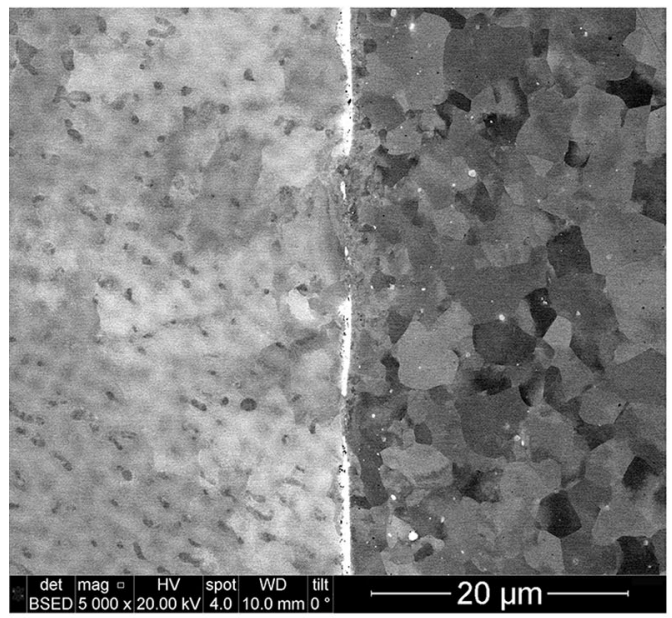

(c)

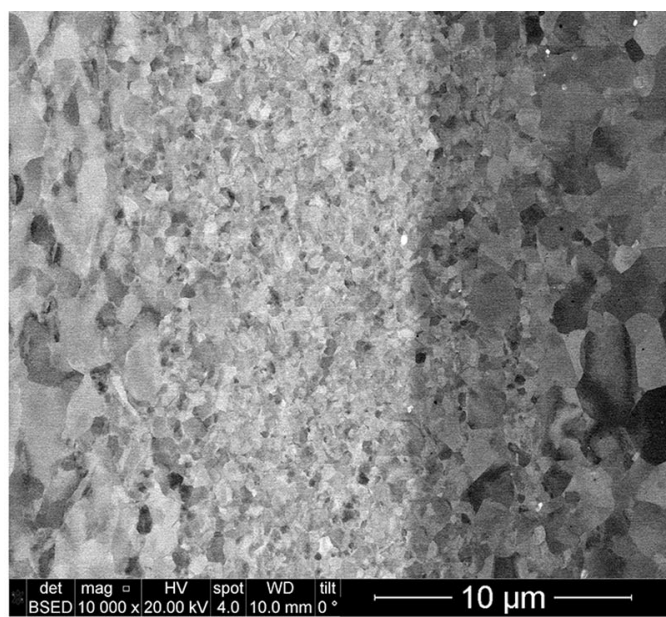

(b)

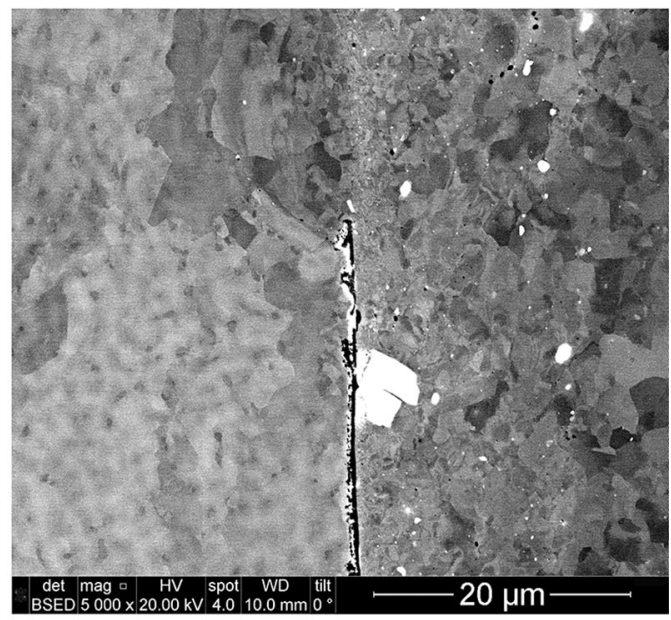

(d)

Fig. 8- SEM backscattered electron images of weld sample LM02 highlighting changes in weld-line morphology (Mar-M247 is on the left, and LSHR is on the right of each image): $(a, b)$ defect-free, dynamically recrystallized layer at the weld interface, $(c)$ long, semi-continuous carbide particles decorating the weld interface, and $(d)$ large remnant carbide particles and cracks along the weld interface.

\section{Mechanical Properties}

\section{Microhardness}

Mirroring the microstructure results, the microhardness measurements also varied axially and radially [Figure $12(r=0 \mathrm{~mm})$ and Figure $13(r=3.3 \mathrm{~mm})$ ]. In each of the figures, LSHR is on the right side of the weld interface annotated by a vertical dotted line. The data showed that the axial hardness profiles of the welded samples depended strongly on the flywheel moment of inertia and the radial position. Sample LM01, which used the flywheel with the lowest moment of inertia, showed a sharp hardness maximum at the weld interface and two local hardness minima: one on each side of the interface, approximately $0.75 \mathrm{~mm}$ from the weld line on the LSHR side, and 0.1 to $0.2 \mathrm{~mm}$ from the weld line on the Mar-M247 side (Figure 12(a)). The minimum on the LSHR side was deeper at the center of the weld $(r=0 \mathrm{~mm})$ than near the OD (Figures 12(a) and 13(a)). The minimum on the Mar-M247 side was deeper and more pronounced at $r=3.3 \mathrm{~mm}$ (Figure 13(a)). The hardness minima disappeared on Mar-M247 side and became very shallow on LSHR side, while the height and breadth of the hardness maximum near the weld interface increased with increased moment of inertia, i.e., samples LM02 and LM03 (Figures 12 and 13). At distances greater than $2 \mathrm{~mm}$ from the weld interface, the hardness on the LSHR side was $\mathrm{Hv}=361 \pm 5$, comparable to that of the parent LSHR, in all of the welded samples. On the Mar-M247 side, the width of the heat-affected zone (HAZ), in which the hardness after welding differed from that of the parent metal $(397 \pm 10 \mathrm{Hv})$, was $\sim 2$ to $3 \mathrm{~mm}$ at $r=0 \mathrm{~mm}$, and $\sim 3$ to $4 \mathrm{~mm}$ at $r=3.3 \mathrm{~mm}$.

\section{Tensile properties}

The tensile properties of the welded samples at three different radial locations (Table IV; Figure 14) provided quantitative insight into the mechanical integrity of the IFW bonds. This information was complemented by measurements of the local axial strain as a function of position along the tension axis (Figure 15); the position of the weld line was indicated by a vertical dashed line with LSHR on the right. In each of the tension tests, 


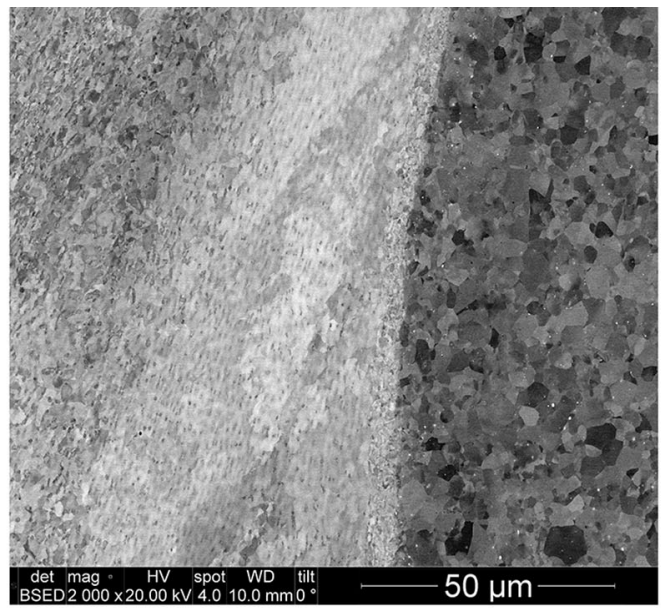

(a)

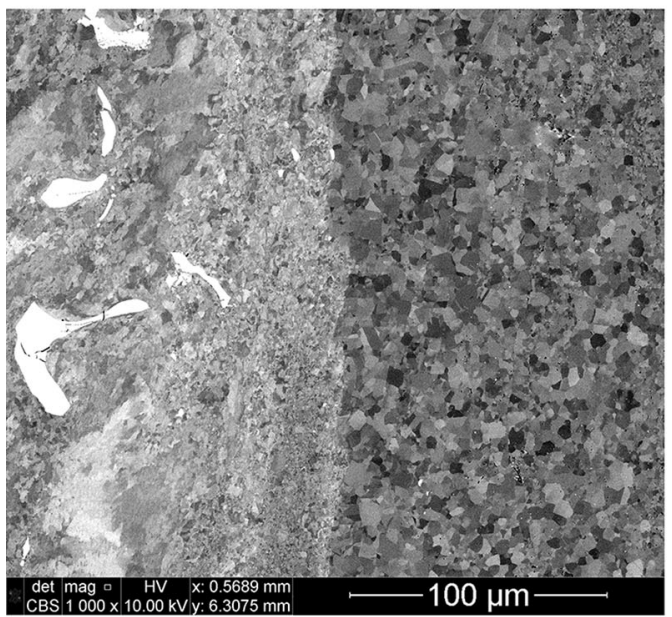

(c)

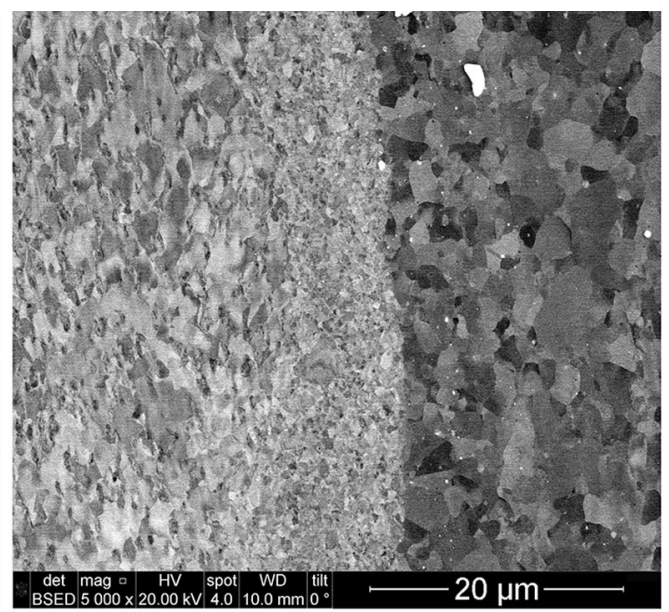

(b)

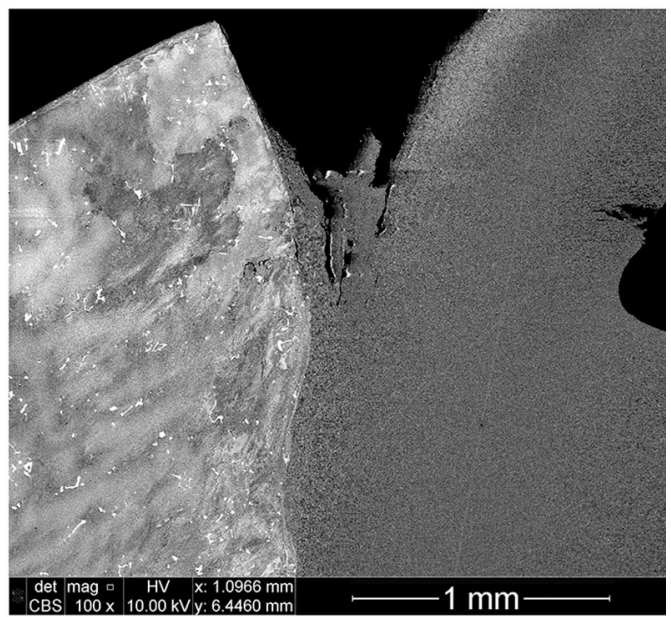

(d)

Fig. 9-SEM backscattered electron images of weld sample LM03 highlighting changes in weld-line morphology (Mar-M247 is on the left, and LSHR is on the right of each image): $(a, b, c)$ defect-free, dynamically recrystallized layer at the weld interface and $(d)$ secondary flash formation and remnant bonded LSHR to the Mar-M247 barreled section.

LSHR did not yield, and all strain was localized within the Mar-M247 portion of the sample (Figure 15).

Tension samples extracted from the center and middle of sample LM01 (i.e., $r=0.7$ and $2.5 \mathrm{~mm}$, respectively) failed along the weld interface at relatively low stress levels (559 and $517 \mathrm{MPa}$, respectively) and did not show any macroscopic plastic strain (Figure 14(a)). The tension sample extracted from the $r=4.3 \mathrm{~mm}$ location of weld LM01 showed noticeable plastic strain. The 0.2 pct yield stress (YS) of this sample was $724 \mathrm{MPa}$, and the sample exhibited continuous strain hardening at the rate $\mathrm{d} \sigma / \mathrm{d} \varepsilon=2800 \pm 200 \mathrm{MPa}$, total elongation (El) of $3.8 \mathrm{pct}$, and an ultimate tensile strength (UTS) of $840 \mathrm{MPa}$ (Figure 14(a)). Extensive strain localization preceded ductile fracture on the Mar-M247 side approximately $7 \mathrm{~mm}$ away from the weld interface (Figure 15(a)).

Among the tension samples extracted from LM02 at three different radial positions, those at $r=0.7$ and $2.5 \mathrm{~mm}$ showed identical ductile behavior, with $\mathrm{YS}=727 \pm 6 \mathrm{MPa}, \quad \mathrm{d} \sigma / \mathrm{d} \varepsilon=2700 \mathrm{MPa}, \quad$ UTS $=$ $827 \pm 15 \mathrm{MPa}$, and $\mathrm{El}=3.7 \pm 0.3$ pct (Figure 14(b);
Table IV). These samples showed noticeable strain localization on the Mar-M247 side and fractured away from the weld interface and the heat-affected zone (Figure 15(b)). However, the sample extracted at $r=4.3 \mathrm{~mm}$ failed along the weld interface at a very low stress level (301 MPa) and did not show any macroscopic strain.

All tension samples extracted from LM03 showed similar ductile behavior, with YS $=733 \pm 5 \mathrm{MPa}, \mathrm{d} \sigma /$ $\mathrm{d} \varepsilon=2700 \mathrm{MPa}, \quad$ UTS $=838 \pm 15 \mathrm{MPa}$, and $\mathrm{El}=$ $2.9 \pm 0.5$ pct (Figure 14(c); Table IV). In these samples, the strain localized and failure occurred on the Mar-M247 size outside the HAZ (Figure 15(c)). Failure outside the HAZ was an indication of complete bonding across the weld interface area.

\section{Fracture surface topography}

Two markedly different fracture surface morphologies were noted in SEM secondary electron (SE) images of the failed tension specimens. For samples which failed in the Mar-M247 side outside the HAZ, the fracture morphology was typical of a moderately-ductile 


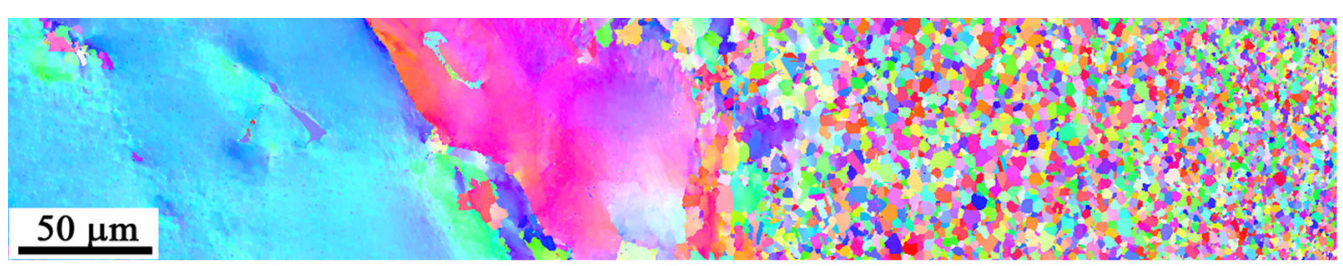

(a)

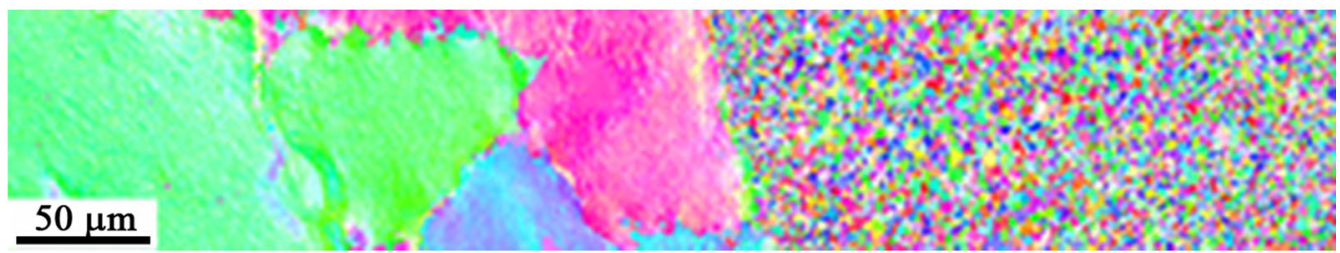

(b)

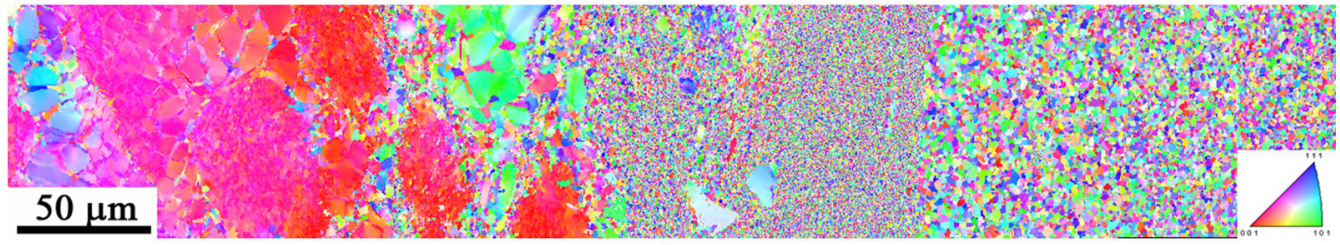

(c)

Fig. 10-EBSD inverse pole figure maps for the transverse direction highlighting the effect of flywheel moment of inertia on recrystallization behavior of Mar-M247 (left) and LSHR (right) at the weld line: (a) LM01 $\left(I=0.166 \mathrm{~kg} \mathrm{~m}^{2}\right),(b) \operatorname{LM} 02\left(I=0.380 \mathrm{~kg} \mathrm{~m}{ }^{2}\right)$, and $(c)$ LM03 $\left(I=0.802 \mathrm{~kg} \mathrm{~m}^{2}\right)$.

Table IV. Tensile Properties of IFW Samples as a Function of Radial Location

\begin{tabular}{|c|c|c|c|c|c|}
\hline Sample ID & $\mathrm{E}(\mathrm{GPa})$ & YS (MPa) & UTS (MPa) & Elongation Pct & Fracture Location \\
\hline \multicolumn{6}{|l|}{ LM01 } \\
\hline$r=0.7 \mathrm{~mm}$ & 211 & - & 559 & 0.3 & weld line \\
\hline$r=2.5 \mathrm{~mm}$ & 220 & - & 517 & 0.22 & weld line \\
\hline$r=4.3 \mathrm{~mm}$ & 216 & 724 & 840 & 3.8 & outside HAZ \\
\hline \multicolumn{6}{|l|}{ LM02 } \\
\hline$r=0.7 \mathrm{~mm}$ & 210 & 722 & 830 & 3.9 & outside HAZ \\
\hline$r=2.5 \mathrm{~mm}$ & 206 & 733 & 824 & 3.5 & outside HAZ \\
\hline$r=4.3 \mathrm{~mm}$ & 201 & - & 301 & 0.2 & weld line \\
\hline \multicolumn{6}{|l|}{ LM03 } \\
\hline$r=0.7 \mathrm{~mm}$ & 205 & 733 & 834 & 2.9 & outside HAZ \\
\hline$r=2.5 \mathrm{~mm}$ & 181 & 735 & 853 & 3.4 & outside HAZ \\
\hline$r=4.3 \mathrm{~mm}$ & 203 & 732 & 828 & 2.4 & outside HAZ \\
\hline
\end{tabular}

material (Figure 16(a)). The fracture surface had a blocky, faceted, and layered appearance. Cleaved surfaces of large fractured carbide particles were also observed suggesting that cracks were initiated inside these particles. The presence of dimples on the faceted surfaces (Figures 16(b), (c)) suggested that the ductile failure mechanism of the $\gamma$ matrix was by cavitation.

By contrast, the fracture surfaces of LM01 $(r=2.7$ and $4.3 \mathrm{~mm})$ and LM02 $(r=4.3 \mathrm{~mm})$, which failed at the weld interface, exhibited a large area of un-bonded material (Figure 17(a)). The un-bonded regions appeared to exhibit wear/rubbing features in a circular pattern suggestive of the rotational motion imposed during IFW. Higher magnification examination revealed the presence of oxide and carbide particles, as well as fine porosity, in these un-bonded regions (Figures 17(b), (c)). The fracture surface regions adjacent to these defects contained a refined grain structure of Mar-M247 and numerous ductile dimples (Figures 17(d), (e)).

\section{DISCUSSION}

The experimental results provided broad insight into the mechanics of the IFW process and the effect of IFW process variables on metal flow, microstructure 


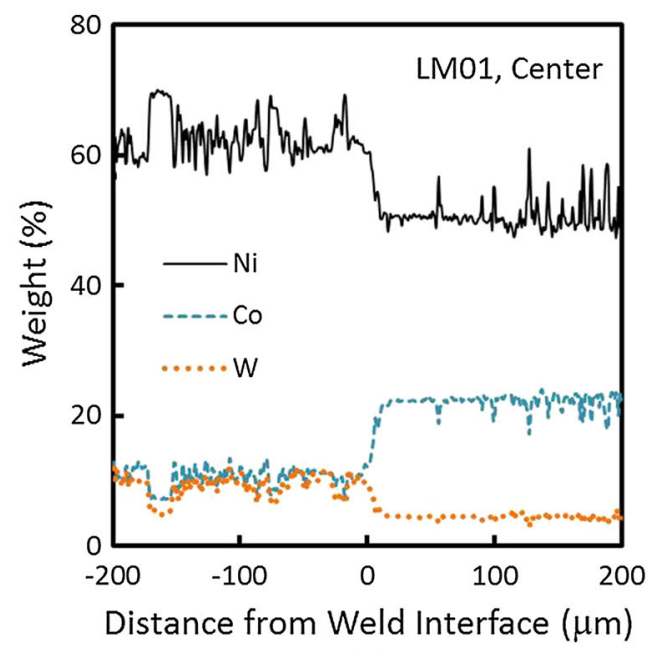

(a)

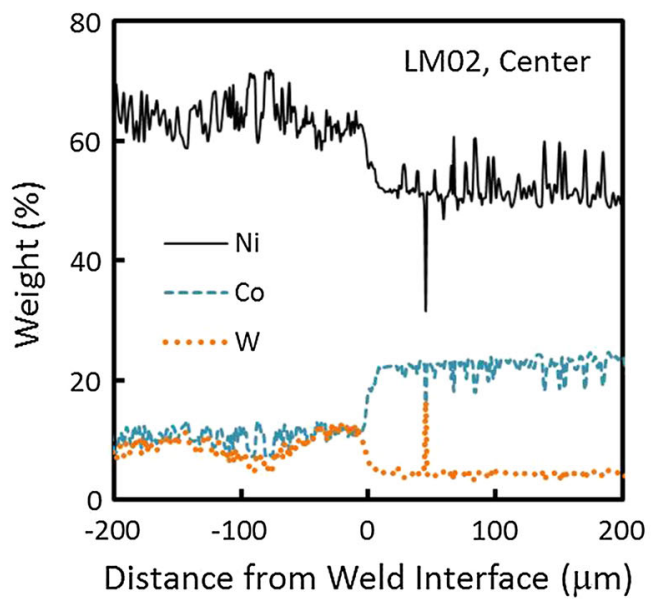

(c)

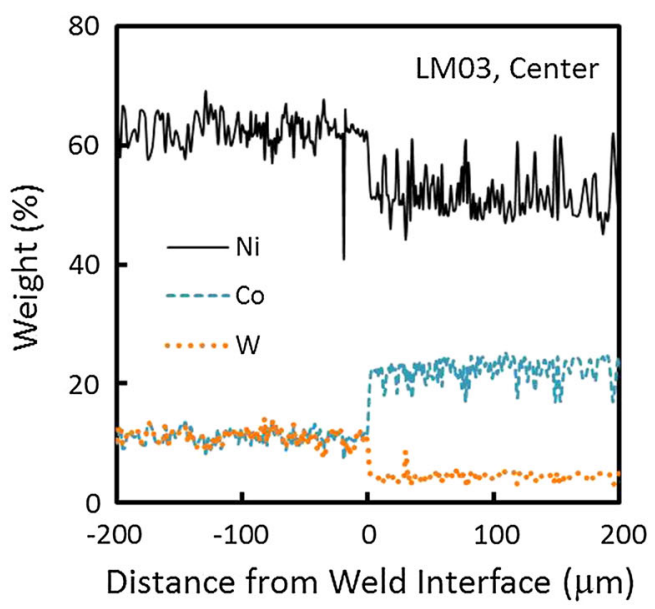

(e)

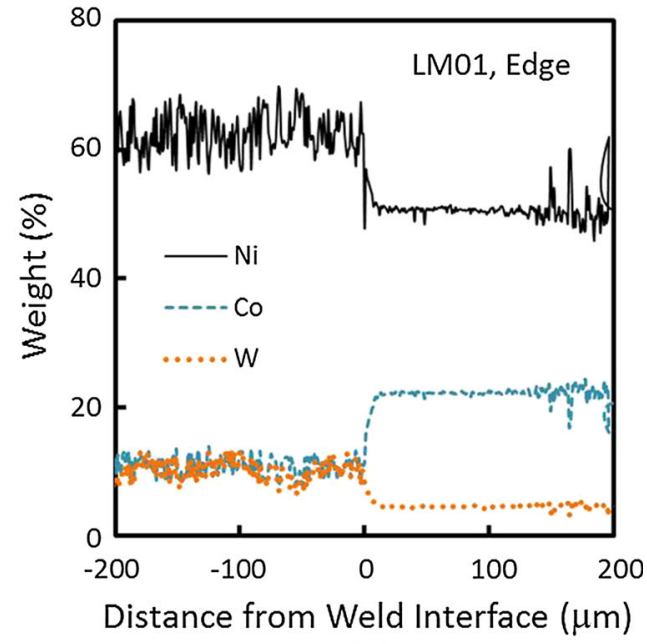

(b)

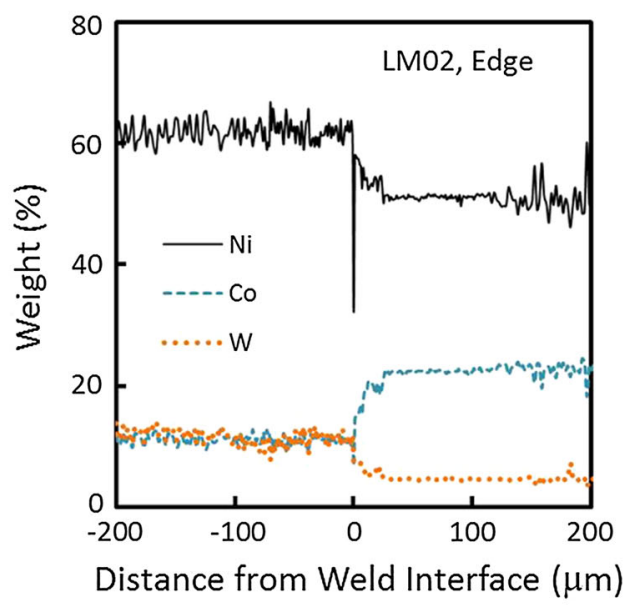

(d)

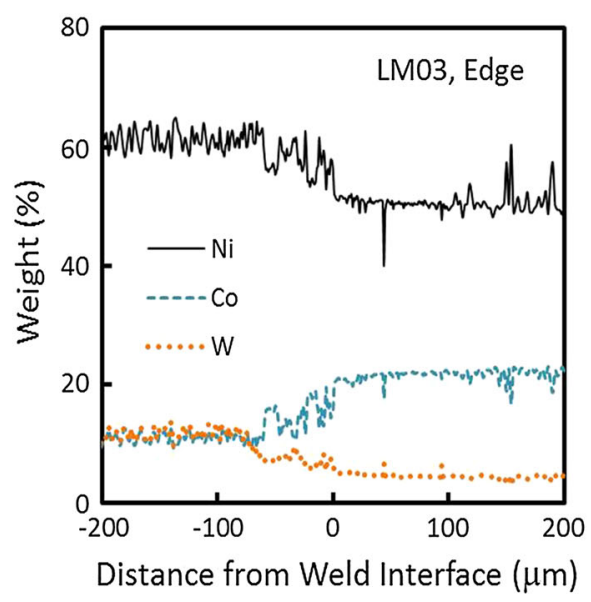

(f)

Fig. 11 - Concentration profiles for $\mathrm{Ni}, \mathrm{Co}$, and $\mathrm{W}$ near the weld interface for samples $(a, b) \mathrm{LM} 01,(c, d) \mathrm{LM} 02$, and $(e, f) \mathrm{LM} 03$ at radial distances $r=0 \mathrm{~mm}$ (center) and $r=4.2 \mathrm{~mm}$ (OD). Mar-M247 is on the left and LSHR is on the right of each profile. 


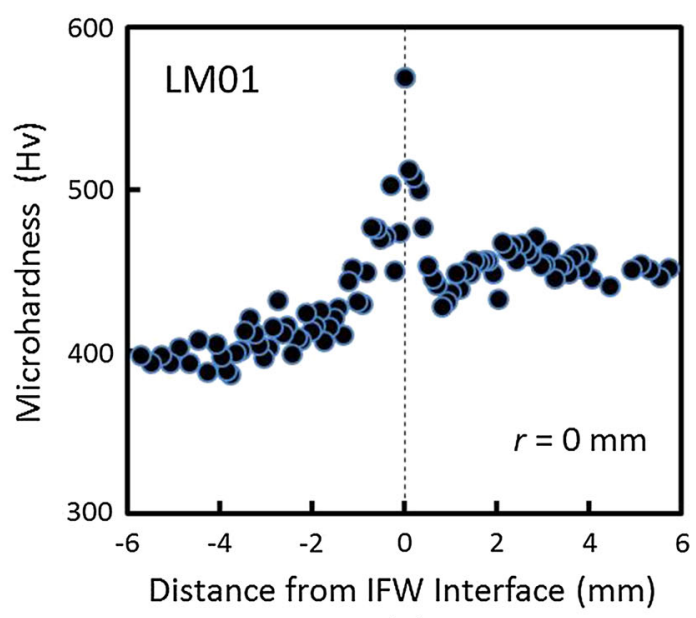

(a)

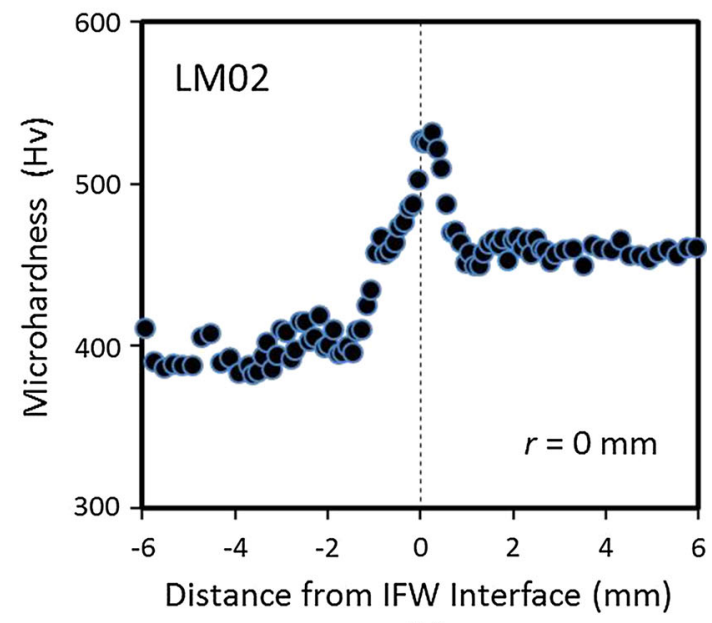

(b)

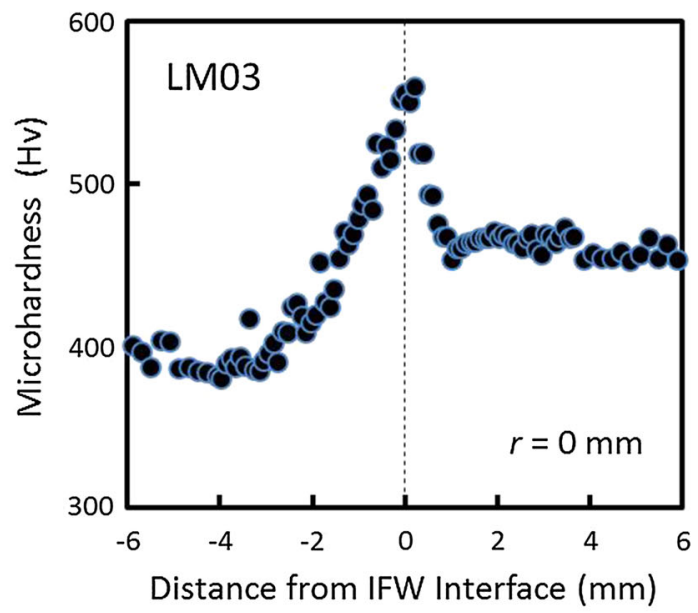

(c)

Fig. 12-Measurements of the Vickers microhardness as a function of distance along the weld centerline in samples $(a)$ LM01, $(b)$ LM02, and (c) LM03. Mar-M247 is on the left side and LSHR is on the right side of each graph.

evolution, and post-formed mechanical properties. These aspects are discussed and interpreted in the following sections.

\section{A. Analysis of IFW with Constant Input Energy and Axial Force}

The present results revealed a number of important details related to IFW process optimization in terms of metal flow, degree of upset, bond quality, and post-weld mechanical properties. It is commonly believed that IFW is controlled by two main parameters: welding energy, $E_{\mathrm{ko}}$, and the axial compression force, $P$. The moment of inertia, $I$, and the initial rotation speed of flywheel, $\omega_{\mathrm{o}}$, are typically selected based on the required welding energy (Eq. [1]) and flywheel mass available for a given IFW machine. ${ }^{[6]}$ The results of the present work revealed, however, that metal flow and microstructure response during IFW of dissimilar superalloys such as LSHR and Mar-M247 depend strongly on I, despite constant $E_{\mathrm{ko}}$ and $P$. In particular, the processing time, deformed volume, maximum temperatures developed in HAZ, and degree of sample upset increased with an increase in $I$. The quality (i.e., integrity and strength) of the welds also improved with increasing $I$. In particular, during post-weld tension testing, welds produced with the highest moment of inertia $\left(I=0.802 \mathrm{~kg} \mathrm{~m}^{2}\right)$ showed significant plasticity beyond the yield point and failure on the Mar-M247 side far from the interface. On the other hand, welds fabricated with the lowest moment of inertia $\left(I=0.166 \mathrm{~kg} \mathrm{~m}^{2}\right)$ exhibited essentially no plastic flow in tension prior to failure at the weld interface at which there were a variety of defects. In the latter samples, the process parameters resulted in a partially bonded condition, likely due to insufficient heating and plastic deformation during welding. Specifically, the Mar-M247 material exhibited minimal upset which resulted in the retention of weld-related defects. Such plastic deformation is required to expel weld surface contaminants into the flash; these contaminants include submicron-sized, often-agglomerated, carbide and oxide particles, which prevent bringing nascent metal into contact to form a sound metallurgical bond.$^{[6,10]}$ The welds produced using the intermediate moment of inertia $\left(I=0.381 \mathrm{~kg} \mathrm{~m}^{2}\right)$ showed a mixed deformation/fracture behavior during post-weld tension testing.

The noticeable effect of $I$ at fixed values of $E_{\mathrm{ko}}$ and $P$ on welding and post-welding behavior can be rationalized by examining the rate of dissipation of the kinetic energy of the flywheel, $\mathrm{d} E_{\mathrm{k}} / \mathrm{d} t$ (Figure 2(b)). The present results showed that the decrease in $E_{\mathrm{k}}$ occurred more rapidly when a smaller flywheel mass was used. In general, the rate of decrease in $E_{k}$ is controlled by the power losses due to friction and the transformation of the kinetic energy into friction-induced heating of both (i) the workpiece samples at the weld interface and (ii) the journal and thrust bearings and the surrounding oil within IFW machine. Although the energy efficiency of IFW equipment has been mentioned as a contributing factor in the description of the IFW process, it appears that the energy losses due to friction in the IFW machine bearings have neither been analyzed nor reported in the literature. ${ }^{[5,10,11]}$

An increase in the fraction of the kinetic energy consumed by the rotating parts of the welding machine 


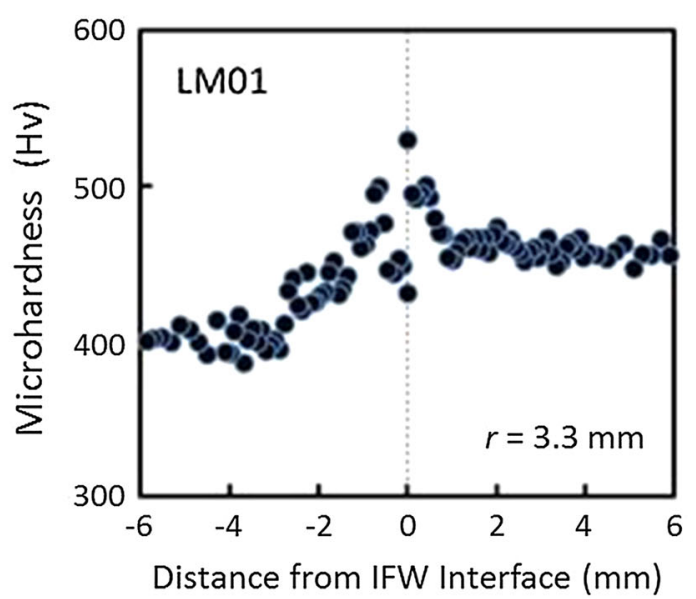

(a)

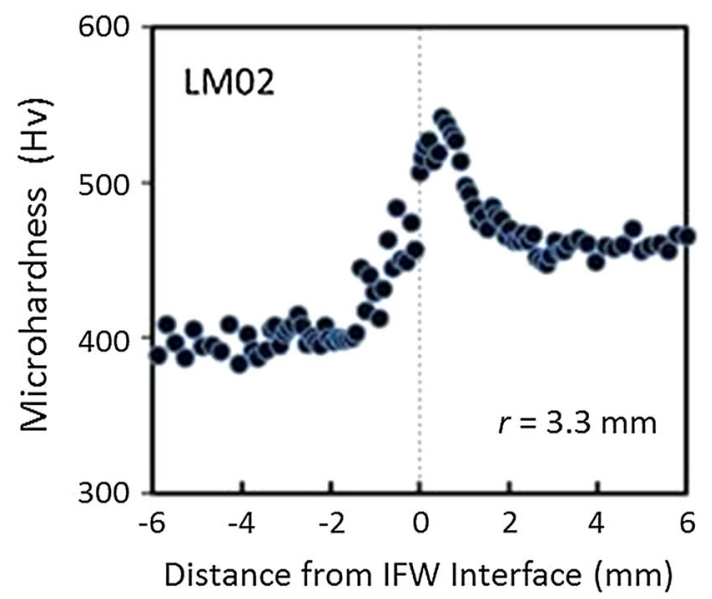

(b)

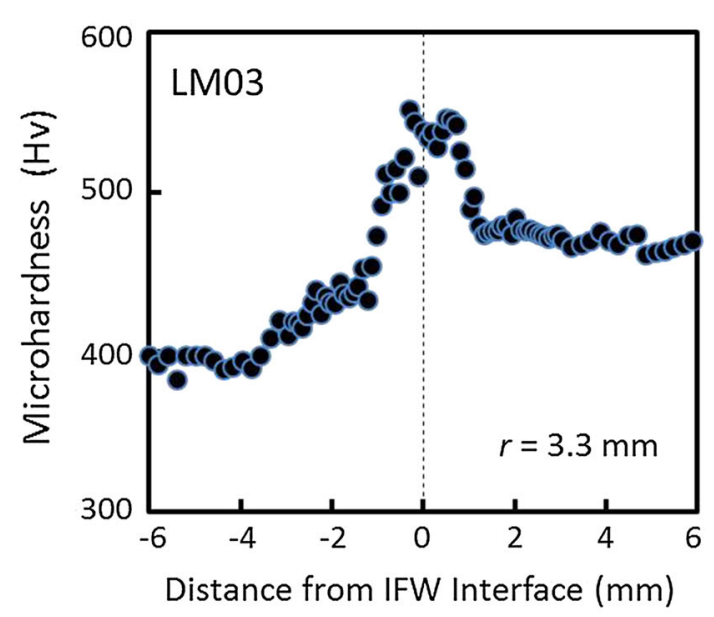

(c)

Fig. 13-Measurements of the Vickers microhardness as a function of distance across the weld OD in samples $(a) \mathrm{LM} 01,(b) \mathrm{LM} 02$, and (c) LM03. Mar-M247 is on the left side and LSHR is on the right side of each graph.

(i.e., parasitic energy losses) results in a decrease in the efficiency of the IFW process due to the reduced level of energy available to heat the contact surfaces of the alloys to be welded. The relative contributions to the rate of energy dissipation can be expressed as

$$
\mathrm{d} E_{\mathrm{S}} / \mathrm{d} t=\mathrm{d} E_{0} / \mathrm{d} t-\mathrm{d} E_{\mathrm{M}} / \mathrm{d} t .
$$

Here, $\mathrm{d} E_{\mathrm{S}} / \mathrm{d} t$ and $\mathrm{d} E_{\mathrm{M}} / \mathrm{d} t$ are the rates of energy dissipation at the weld interface surface and within the welding machine, respectively. If the respective friction-induced torque values, $T_{\mathrm{S}}$ and $T_{\mathrm{M}}$, are known, these quantities can be calculated from the general relationship:

$$
d E / d t=T \omega .
$$

For cylindrical workpieces, the torque, $T_{\mathrm{S}}$, at the weld interface is determined by the product of the effective friction coefficient, $\mu_{S}$, applied axial compression force $P$, and the outer radius of the workpieces, $r_{\mathrm{o}},{ }^{[4,12]}$ i.e.,

$$
T_{\mathrm{S}}=2 \mu_{\mathrm{S}} \operatorname{Pr}_{\mathrm{o}} / 3 \text {. }
$$

For the machine losses, $T_{\mathrm{M}}$ is the sum of the journal bearing torque $T_{\mathrm{JB}}$ and thrust bearing torque $T_{\mathrm{TB}}$, which can be expressed as follows: ${ }^{[13-15]}$

$$
\begin{aligned}
& T_{\mathrm{JB}}=\left(2 \pi v R_{1}^{3} L / h_{1}\right) \omega, \\
& T_{\mathrm{TB}}=\left(2 \pi v R_{2}^{4} / 3 h_{2}\right) \omega .
\end{aligned}
$$

Here, $v$ is the oil viscosity, $R_{1}$ is the shaft radius, $L$ and $h_{1}$ are the length and radial clearance of the journal bearing, and $R_{2}$ and $h_{2}$ are the effective surface radius and oil film thickness of the thrust bearing. If it is assumed that these values are constant during the steady-state portion of welding, $T_{\mathrm{M}}$ can be expressed as a linear function of $\omega$, i.e.,

$$
T_{\mathrm{M}}=C_{1} \omega .
$$

Here, $C_{1}=2 \pi v\left(R_{1}^{3} L / h_{1}+R_{2}^{4} / 3 h_{2}\right)$ is a parameter that depends on the configuration of the bearings, oil viscosity, and, perhaps, the axial compression force $P$ (through its effect on $h_{2}$ ).

Combining Eqs. [6] and [10], the parasitic energy losses inside the welding machine can be calculated as

$$
E_{\mathrm{M}}=\int_{0}^{t_{\max }} C_{1} \omega^{2} \mathrm{~d} t .
$$

In Eq. [11], $t_{\max }$ denotes the duration of the IFW process (i.e., the time interval between the instant when the sample surfaces are brought together at the rotational velocity $\omega=\omega_{0}$ and that when the flywheel rotation stops, $\omega=0$ ). To perform the integration in Eq. [11], it was assumed as a first approximation that $\omega$ decreases linearly with time (per Figure 2(a)), or

$$
\omega=\omega_{0}-\text { at. }
$$




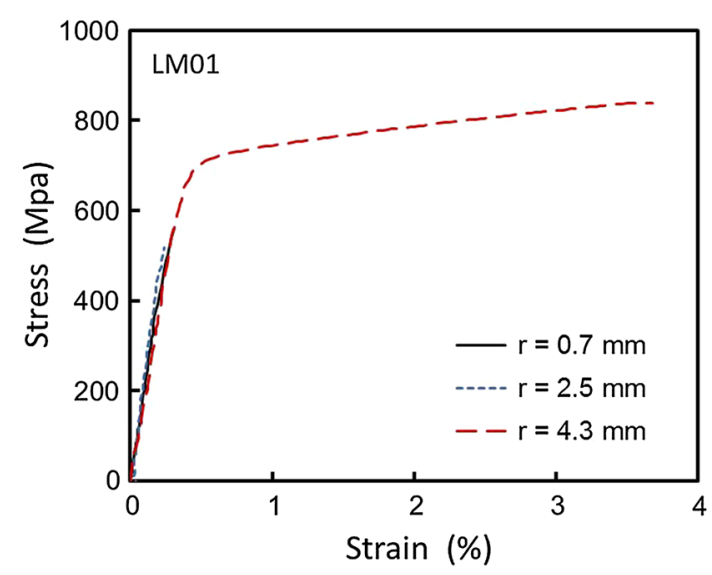

(a)

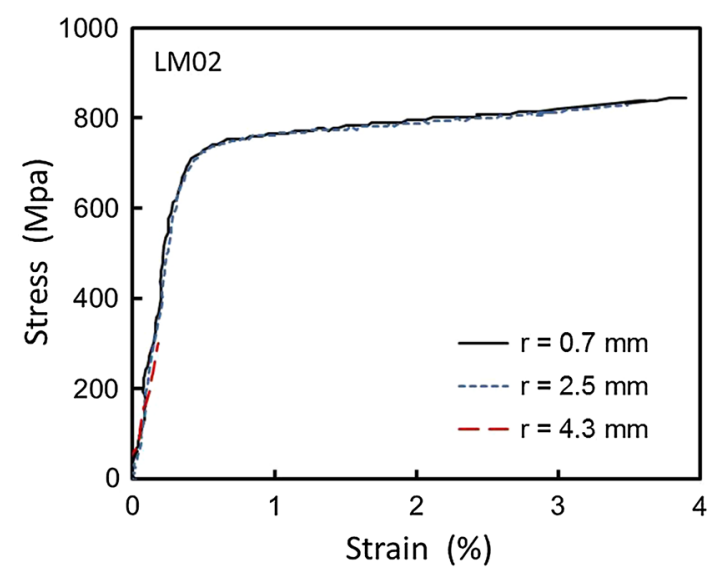

(b)

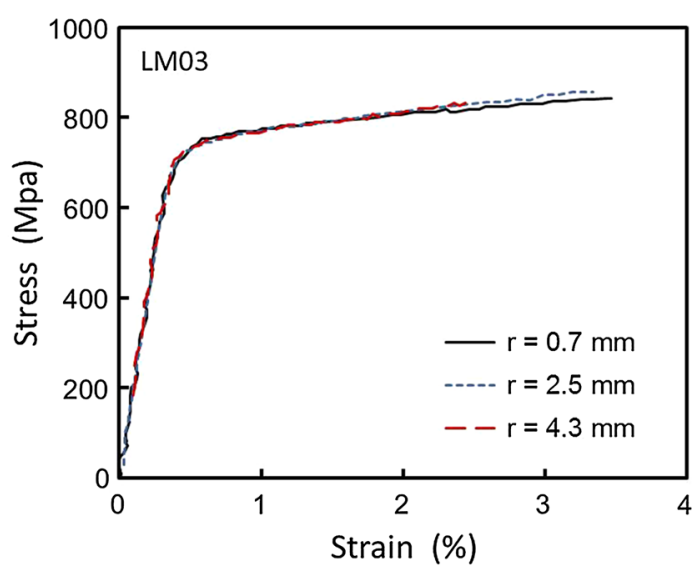

(c)

Fig. 14 -Tension stress-strain curves for $(a)$ LM01, $(b)$ LM02, and (c) LM03 at different radial locations $(r=0.7,2.5$, and $4.3 \mathrm{~mm})$.

Inserting this expression into Eq. [11], integrating, and applying Eq. [1] yield the following relation:

$$
E_{\mathrm{M}}=\frac{C_{1} \omega_{o}^{2} t_{\max }}{3} \equiv \frac{2 C_{1} E_{\mathrm{ko}} t_{\max }}{3 I} .
$$

Taking into account the fact that the welding trials were conducted with identical values of $E_{\mathrm{ko}}$, the process efficiency, $\eta$, can then be estimated using the following formula:

$$
\eta=1-E_{\mathrm{M}} / E_{\mathrm{ko}}=1-\frac{2 C_{1} t_{\max }}{3 I} .
$$

Equation [14] reveals that $\eta$ increases with the decreasing $t_{\max }$ and increasing $I$. The present experimental data (Figure 2(a)) indicated that when $I$ increased $\sim 4.83$ times (from 0.166 to $0.802 \mathrm{~kg} \mathrm{~m}^{2}$ ), $t_{\max }$ increased $\sim 2.45$ times (from 4 to 9.8 seconds). Thus, the quotient $t_{\max } / \mathrm{I}$ decreased by a factor of $\sim 2$. Therefore, the efficiency of the IFW process increased with an increase in the flywheel moment of inertia, even though the total welding energy, $E_{\mathrm{ko}}$, had remained constant. This analysis thus provides a plausible explanation why increasing $I$ at constant $E_{\mathrm{ko}}$ results in welds with more pronounced flash, more extensive deformation, and improved weld quality.

The analysis above also enables quantitative estimation of $\mu_{\mathrm{S}}, C_{1}$, and $\eta$. Specifically, combining Eqs. [7] and [10], the following relation for the total torque is obtained:

$$
T=\frac{2 \mu_{\mathrm{S}} r_{\mathrm{O}} P}{3}+C_{1} \omega
$$

A comparison of Eqs. [4] and [15] reveals that the friction coefficient at the weld interface during the steady-state stage of the IFW process $\left(\mu_{\mathrm{SS}}\right)$ is constant and exhibits a weak dependence on the IFW parameters, at least for the present IFW conditions and alloys, i.e.,

$$
\mu_{\mathrm{SS}}=\frac{3 T_{\mathrm{o}}}{2 r_{\mathrm{o}} P} \approx 0.050 \pm 0.005 .
$$

The comparison of Eqs. [4] and [15] also enables an estimation of the coefficient $C_{1}$, i.e.,

$$
C_{1}=\tau T_{\mathrm{o}} \approx 0.020 \pm 0.003 \mathrm{~kg} \mathrm{~m}^{2} \mathrm{~s} .
$$

Assuming that $C_{1}$ is time independent, the temporal dependence of the friction coefficient at the weld interface, $\mu_{\mathrm{S}}$, is determined from Eq. [15] by subtracting the machine bearing torque, $T_{\mathrm{M}}=C_{1} \omega$, from the total torque, $T=I a$, thereby resulting in the following expression:

$$
\mu_{\mathrm{S}}=\frac{3}{2} \frac{I a-C_{1} \omega}{r_{\mathrm{o}} P} .
$$

As expected, the value of $\mu_{\mathrm{S}}$ during IFW (with constant $E_{\mathrm{ko}}$ and $P$ ) was only weakly dependent on the moment of inertia of the flywheel during the first half of the welding period, i.e., $\mu_{\mathrm{S}}=\mu_{\mathrm{SS}} \approx 0.05$ (Figure 18). Subsequently, it increased rapidly and approached a maximum value of $\sim 0.12$ to 0.14 at the end of welding. 


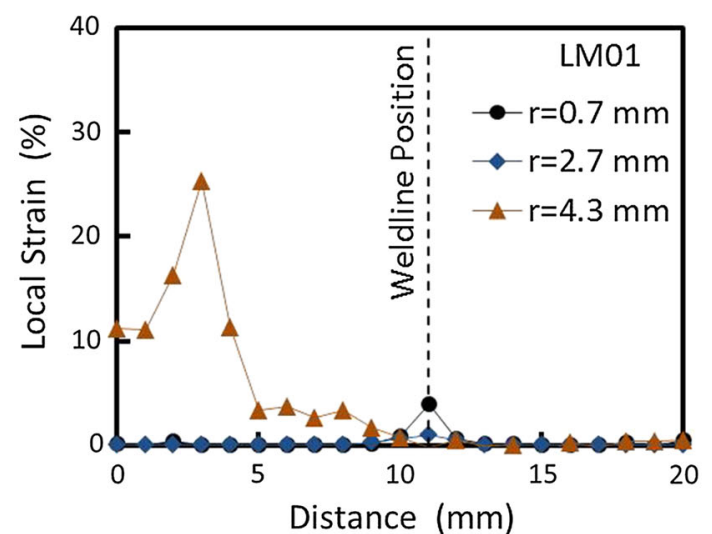

(a)

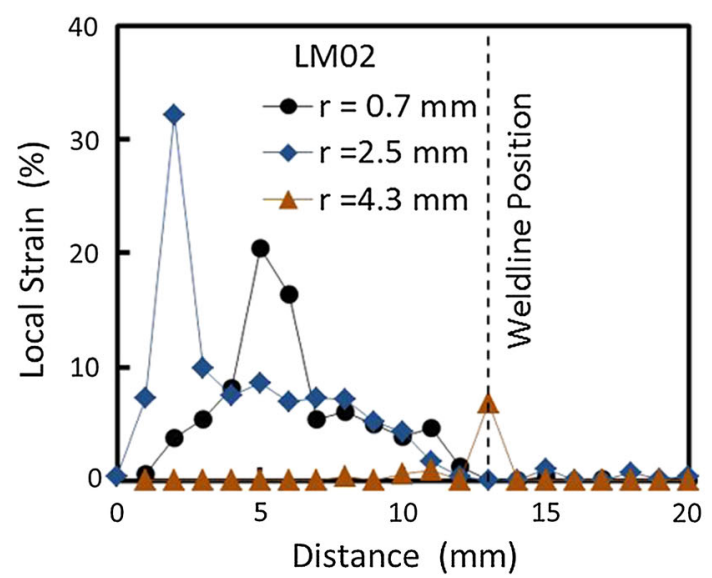

(b)

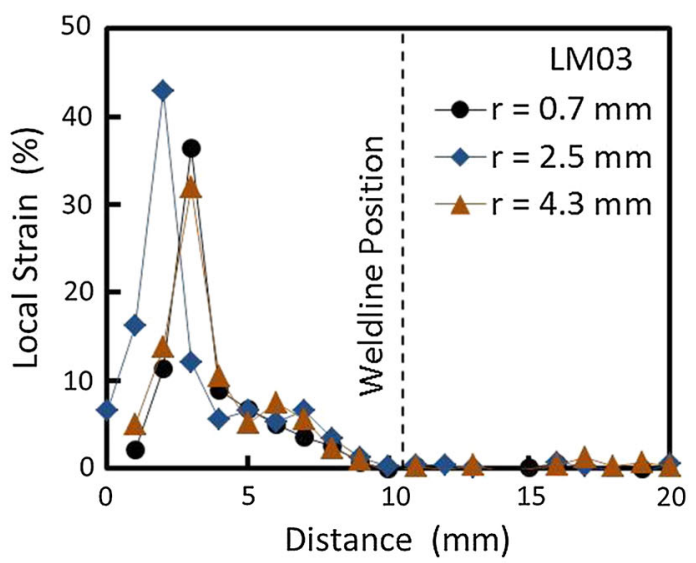

(c)

Fig. 15-Distributions of the local axial strain along the gage length of tension samples extracted from samples $(a)$ LM01, $(b)$ LM02, and (c) LM03 at three radial locations $(r=0.7,2.5$, and $4.3 \mathrm{~mm})$. Mar-M247 is on the left and LSHR is on the right of each graph.

Using Eq. [14] with $C_{1}=0.02 \mathrm{~kg} \mathrm{~m}^{2} \mathrm{~s}$ and experimental values for $t_{\max }$ (Figure 2), the efficiency of the IFW process was estimated to be $\eta=0.68,0.74$, and 0.84 for $I=0.166,0.381$ and $0.802 \mathrm{~kg} \mathrm{~m}^{2}$, respectively. These values for the IFW process efficiency are significantly lower than estimates (0.9 to 1.0$)$ reported previously. ${ }^{[16-18]}$ However, the present FEM results for
IFW do predict the observed upset behaviors (Figure 5(b)) if $\eta$ is assumed to be increased with $I$.

The noticeable dependence of $\eta$ on IFW process parameters identified in this work has not been considered in previous publications. ${ }^{[5,6,10,11,16]}$ Rather, a constant efficiency has typically been assumed in order to interpret and model IFW and to quantify process parameters such as required energy input, degree of flash formation, and extent of sample shortening. ${ }^{[16,18,19]}$ It appears that this assumption has thus led to incorrect conclusions comprising the following: (1) $E_{\mathrm{ko}}$ is the principal parameter controlling IFW, and (2) different combinations of $I$ and $\omega_{\mathrm{o}}$ which provide the same value of $E_{\mathrm{ko}}$ have a negligible effect on the thermal and deformation behavior during IFW.

For welds performed at constant $E_{\mathrm{ko}}$ and $P$, an increase in $I$ increases the duration of the IFW process, which occurs at slower rotation speeds. Therefore, a smaller fraction of $E_{\mathrm{ko}}$ is consumed by the parasitic (friction) work associated with the drive shaft and machine bearings, inasmuch as this work is the product of the square of the rotation speed and duration Eq. [13]. At least for the specific combination of superalloys used here, the simultaneous increase in efficiency and the duration of IFW is beneficial in developing plastic flow in the harder Mar-M247 side. Indeed, increasing $\eta$ indicates that a higher fraction of $E_{\mathrm{ko}}$ is used to heat the weld surfaces, and therefore, a higher peak temperature is achieved. ${ }^{[16,18]}$ Also, increasing $t_{\max }$ results in increased weld duration in the processing temperature range (Figure 5), thereby leading to a larger volume of material that is deformed plastically. The longer duration of the IFW process at higher $I$ also gives rise to an increased degree of recrystallization in Mar-M247 near the weld line (Figure 10) and to an increased width of the transition region inside which mechanical mixing of LSHR and Mar-M247 occurs (Figure 11). Additional increases in weld duration could further increase the level of deformation and recrystallization in Mar-M247 and promote improved bonding. Another attractive process alternative might include a reduction in the applied axial load in order to increase the temperature at the weld interface and further promote plasticity in Mar-M247. ${ }^{[6]}$ Reducing the axial load, however, may not have a significant impact on weld temperature, inasmuch as LSHR has a lower $\gamma^{\prime}$ solvus temperature and reduced strength at elevated temperatures compared to Mar-M247. Therefore, the maximum temperature achievable at the weld interface would likely be limited by plastic flow of LSHR. Nevertheless, methods to reduce the flow stress difference between the workpiece materials could prove useful and are worthy of further investigation.

\section{B. Post-weld Properties}

From a broad perspective, the results of the hardness measurements for samples LM01, LM02, and LM03 were similar to previous observations ${ }^{[4]}$ and can be explained on the basis of the evolution of the $\gamma^{\prime}$ precipitate size and $\gamma$ grain size during welding and 


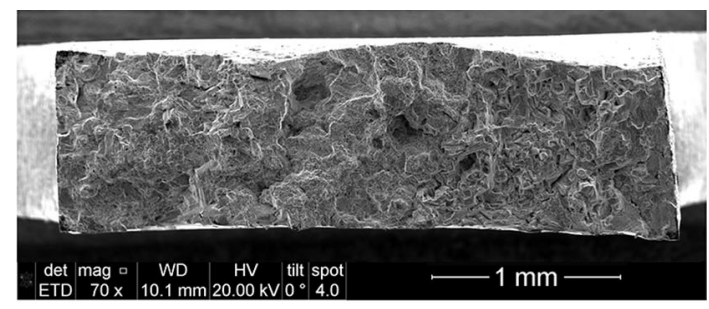

(a)

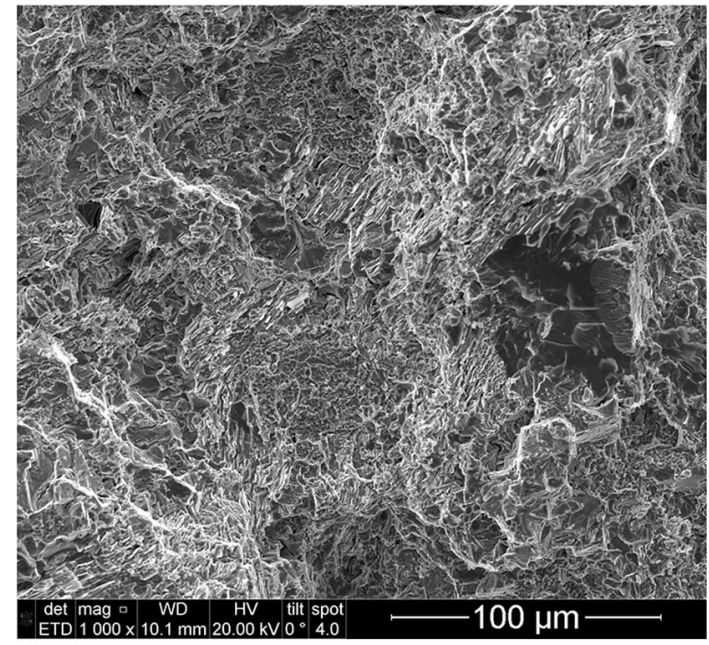

(b)

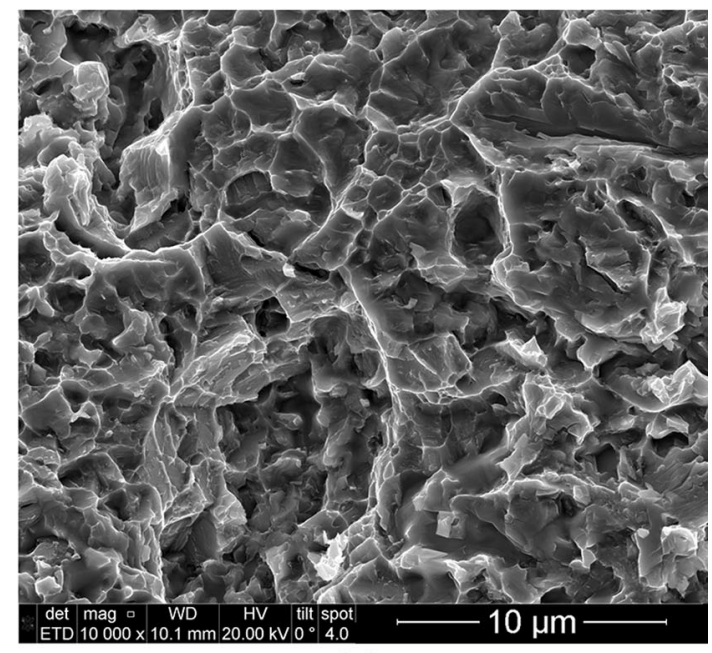

(c)

Fig. 16 - SEM secondary electron images of the fracture surface of tension sample LM03-2 which failed outside the HAZ on the Mar-M247 side: $(a)$ entire fracture surface at low magnification, and higher magnification images illustrating (b) a cellular, faceted appearance of fracture, and $(c)$ dimples on the faceted surfaces.

post-weld cooling. The higher hardness in the HAZ region compared to the parent Mar-M247 and LSHR alloys was probably due to grain refinement as well as dissolution of the coarse primary and secondary $\gamma^{\prime}$ particles during the welding process and re-precipitation of finer particles from the supersaturated $\gamma$ matrix during cool-down after welding. This change in size, distribution, and volume fraction of $\gamma^{\prime}$ particles along with a noticeable decrease in the $\gamma$ matrix grain size could account for the observed hardness maximum at the weld interface. ${ }^{[20]}$ The formation of a $\sim 10$ to $100 \mu \mathrm{m}$ wide, apparently precipitation-free layer in LSHR at the weld line indicates that the peak temperature at the weld interface was above the non-equilibrium, on-heating $\gamma^{\prime}$ solvus, and thus, all of the $\gamma^{\prime}$ precipitates went into solution inside this layer (Figure 11). With an increase in the distance from the weld interface, the peak temperature gradually decreased, which resulted in a smaller fraction of $\gamma^{\prime}$ which had dissolved in the matrix and then re-precipitated during cooling. This reasoning thus explains the observed continuous decrease in hardness from the peak value at the weld interface to the value(s) characteristic of the parent alloy(s) beyond the HAZ. The small local minimum in the hardness of LSHR observed near the center $(r=0)$ at an axial distance of $\sim 1.0 \mathrm{~mm}$ from the weld interface (Figure 12) was likely related to coarsening of the secondary and tertiary $\gamma^{\prime}$ particles relative to the initial condition. This situation can happen when the welding temperature in this region is slightly below the isothermal forging temperature. The minimum hardness in LSHR became less pronounced with increases in the flywheel $I$ and radial distance $r$ (Figures 12 and 13); both factors favor higher peak temperatures and longer duration at peak temperature. Similar reasoning can be used to explain the drop in hardness at the weld line for the Mar-M247 side of sample LM01 at $r=3.3 \mathrm{~mm}$. Here, it appears that the temperatures achieved at all regions near the interface were below the $\gamma^{\prime}$ solvus, so the overall observations can be explained by the competition between coarsening of secondary $\gamma^{\prime}$, partial dissolution of primary $\gamma^{\prime}$ during heating, and re-precipitation of finer particles during cooling. Because the volume fraction of secondary $\gamma^{\prime}$ was very small, the overall trend was an increase in hardness within the HAZ after welding relative to the parent Mar-M247.

The tensile properties provided clues to the effect of defects on weld quality. Samples LM01 and LM02 contained bond-line defects across a portion of their weld interface area, whereas no apparent defects were detected at the weld interface of sample LM03. The lack of bonding apparent on the fracture surfaces of several tension samples extracted from the welds correlated well with the as-welded defects. Furthermore, there appeared to be a correlation between the quality of the bond and the rotation speed/moment of inertia during welding. For the conditions investigated in the present work, the fraction of un-bonded region decreased as the flywheel moment of inertia increased (at constant initial kinetic energy of the flywheel $E_{\mathrm{ko}}$ ). The decrease in weld-line defects can be directly related to an increase in the process efficiency. Indeed, the source of the un-bonded regions was the apparent lack of gross plasticity and deformation along the weld interface in Mar-M247. With an increase in the flywheel moment of inertia, the efficiency of the IFW machine in converting the kinetic energy of the flywheel to frictional heating at the weld interface increased from 68 pct for weld LM01 to $85 \mathrm{pct}$ in weld LM03. The increased heating at the weld interface along with increased weld processing time 


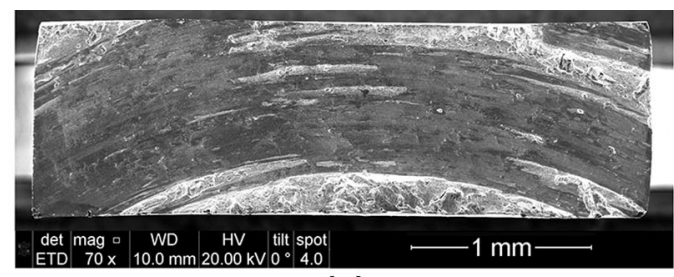

(a)

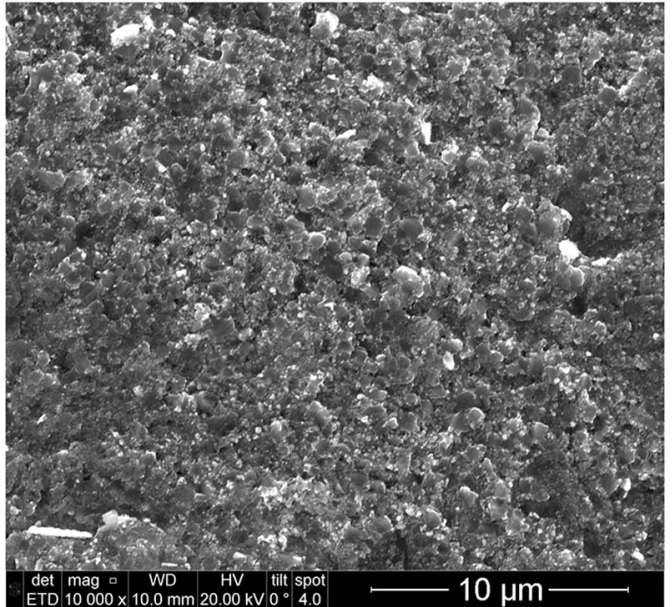

(b)

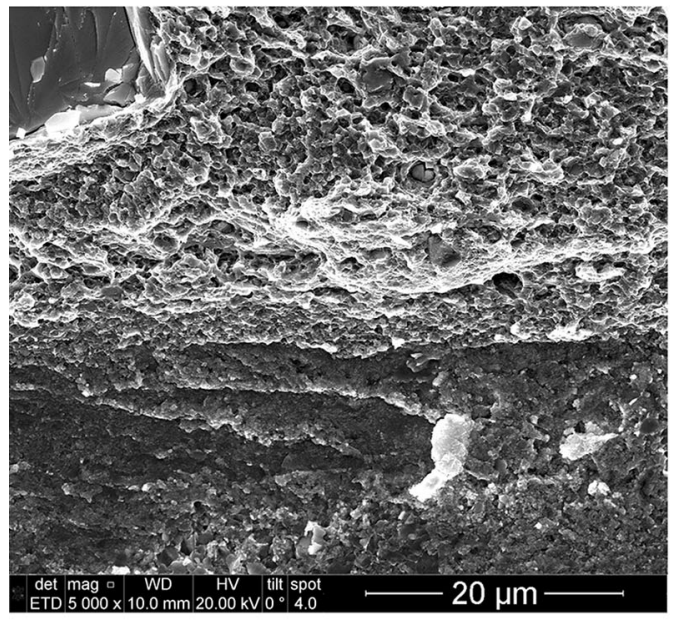

(d)

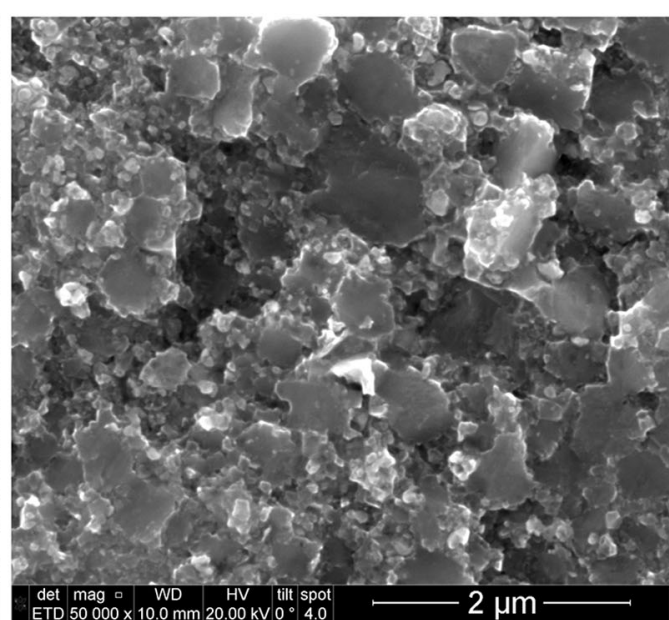

(c)

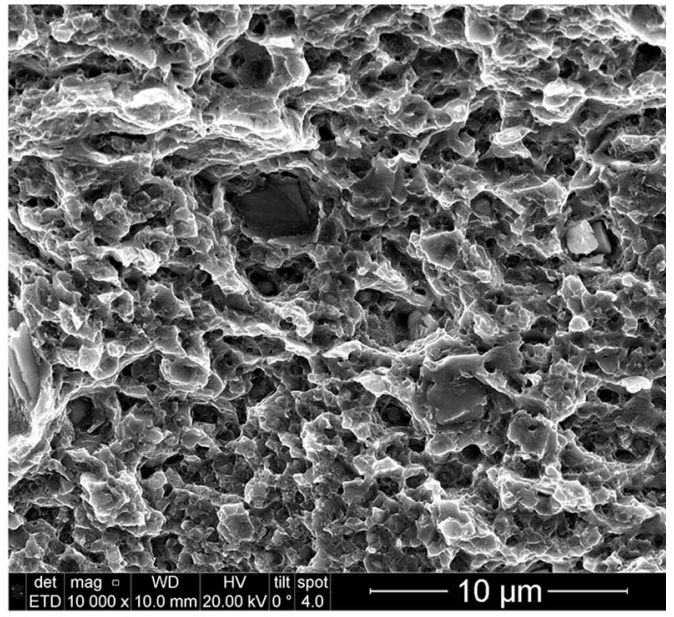

(e)

Fig. 17-SEM secondary electron images of the fracture surface of tension sample LM02-3 which failed at the weld interface: $(a)$ entire fracture surface with a circular welding defect at low magnification, $(b, c)$ submicron-size carbide and oxide particles and flakes on the surface of the welding defect, $(d)$ transition from poorly bonded (bottom) to bonded (top) regions, and $(e)$ ductile fracture of the bonded region.

resulted in a higher peak temperature at the weld interface and deeper heating axially from the weld line. As a result, a larger volume of Mar-M247 experienced plastic deformation and mechanical mixing with LSHR. Although the radial flow of Mar-M247 was limited, extensive mechanical mixing of the mating surface layers due to circumferential and axial plastic flow in weld LM03 was effective in dispersing submicron-size oxide and carbide particles from the interface into the bulk. This dispersal reduced the amount of un-bonded area due to these defects.
Another important observation from the tension tests was the change in the radial dependence of the weld interface strength with a change in $I$. For example, fracture occurred at the weld interface without any evidence of plastic strain in weld LM01 at $r<4.3 \mathrm{~mm}$. However the tension sample extracted at $r=4.3 \mathrm{~mm}$ showed noticeable strength/ductility and fractured outside the HAZ. The weld interface of LM02 exhibited some plasticity at $r=0.7$ and $2.5 \mathrm{~mm}$, but none at $r=4.3 \mathrm{~mm}$. The weld interface of LM03 exhibited plasticity at all radial locations. Detailed analysis of the 


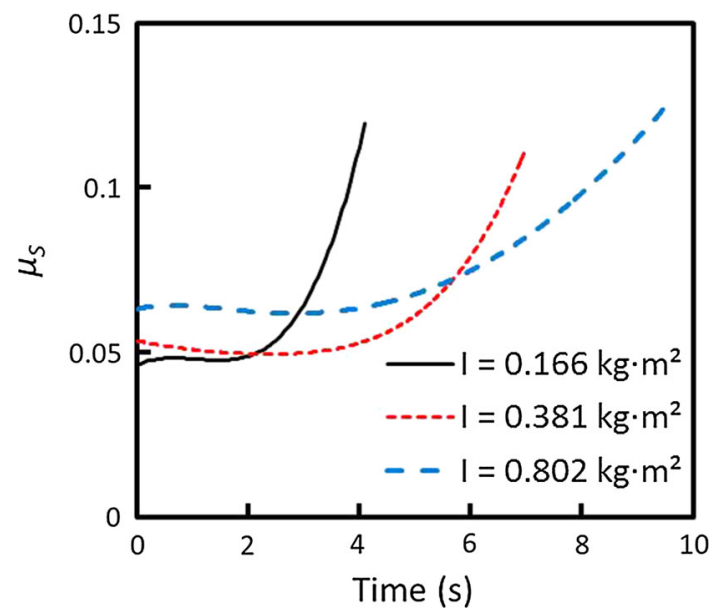

Fig. 18-The dependence of the effective friction coefficient between LSHR and Mar-M247, $\mu_{\mathrm{S}}$, on processing time during IFW with three different flywheel moments of inertia and a constant weld energy, $E_{\mathrm{ko}}=22.2 \mathrm{~kJ}$. The friction coefficient was calculated using Eq. [18] after subtracting the torque due to losses associated with the IFW machine bearings.

fracture surfaces of LM01 revealed that the defects responsible for the fracture of LM01 at the weld interface were extensive porosity and agglomerated submicron-size carbide/oxide particles at $r=0.7 \mathrm{~mm}$ and a continuous carbide layer, as well as cracking along this layer, at $r=2.5 \mathrm{~mm}$. The weld interface of the tension sample extracted at $r=4.3 \mathrm{~mm}$ was almost defect free. In tension samples extracted from LM02, welding defects were identified at $r=4.3 \mathrm{~mm}$ only. Such differences in behavior can be explained by changes in weld duration. The short duration of the IFW process in LM01 did not allow sufficient heating of the center region because of limited thermal diffusion from the OD toward the center, whereas the OD region was heated faster due to faster linear rotation speed. In LM02, longer welding time and extensive plastic flow resulted in hotter OD material moving into the flash and a more homogeneous radial distribution of temperature. The radial plastic flow also moved contaminants from the center of the weld interface toward OD, thus weakening the OD region.

\section{CONCLUSIONS}

Inertia friction welding of LSHR to Mar-M247 under conditions of constant welding energy, $E_{\mathrm{ko}}$, and axial compression force, $P$, but different flywheel moments of inertia, $I$, were conducted to establish the effect of $I$ on the efficiency of the IFW process and the quality of bonds of dissimilar superalloys. From this work, the following conclusions were drawn:

1. The metal flow and microstructure response during IFW of the dissimilar superalloys depend strongly on $I$, despite constant $E_{\mathrm{ko}}$ and $P$. In particular, the processing time, deformed volume, maximum temperature developed in HAZ, and the length of sample upset increase with an increase in $I$. At a given welding energy, the weld quality (i.e., integrity and strength) improves with increased $I$.

2. The lack of bonding at the weld interface, prevalent in welds where small moments of inertia are utilized, is associated with limited plasticity of Mar-M247 which has a higher $\gamma^{\prime}$-solvus temperature and higher hot-working flow stress in comparison to LSHR. Limited metal flow leads to trapping of remnant oxide and carbide particles at the weld interface which is associated with poor bond quality and poor post-IFW tensile strength.

3 . The simultaneous increases in the maximum temperature at the weld interface and the duration of IFW with increased $I$ promote increased plastic flow and dynamic recrystallization of a larger volume on the Mar-M247 side. The fine-grain structure formed at the weld interface effectively reduced the high-temperature yield strength of Mar-M247 and promoted more extensive deformation and flow of the material at the weld interface. As a result, the weld interface was free of the oxide and carbide particles and associated weld defects that are detrimental to bond quality.

4. The significant effect of $I$ (at fixed values of $E_{\mathrm{ko}}$ and $P$ ) on welding and post-welding behavior was rationalized by its influence on the amount of energy lost to friction of the rotating components of the welding machine. It was established that an increase in the flywheel moment of inertia decreased the fraction of the weld energy lost to parasitic sinks within the IFW machine. Therefore, increased moment of inertia increased the efficiency of the conversion of the kinetic energy of the flywheel to thermal energy at the weld interface. Therefore, careful consideration of both $I$ and $\omega$ must be given when determining weld process parameters, simply assuming parameters based only on input energy is not sufficient.

5. The efficiency of the IFW process must be quantified in order to fully define the interrelation between the IFW process parameters and their effects on weldability and weld quality.

6. The apparent change in behavior at the weld line from sliding friction to sticking condition occurred at approximately the same number of revolutions of the weld sample during IFW. During sliding friction, the apparent coefficient of friction between the welding surfaces was very low, $\mu_{\mathrm{S}} \approx 0.05$, and had a minor dependence on the rotational velocity and moment of inertia. When the sticking condition occurred at the end of the welding process, the apparent coefficient of friction increased rapidly and approached the values of $\sim 0.12$ to 0.14 .

\section{ACKNOWLEDGMENTS}

Inertia friction welding was conducted at the Edison Welding Institute, Columbus, Ohio. The authors thank Mr. D. Workman (EWI) for welding assistance. The 
authors also thank Scientific Forming Technologies Corporation for providing the DEFORM finite element software used in this effort. ONS acknowledges the financial support through the Air Force on-site contract FA8650- 10-D-5226 conducted by UES, Inc., Dayton, $\mathrm{OH}$.

\section{REFERENCES}

1. M. Preuss, A. Steuwer, P. J. Withers, G. J. Baxter and S. Bray, In Trends in Welding Research: Proceedings of the 6th International Conference, April 15, 2002-April 19, 2002, (ASM International: Phoenix, AZ, United states, 2002), pp 886-90.

2. Z.W. Huang, H.Y. Li, M. Preuss, M. Karadge, P. Bowen, and S. Bray: Metall. Mater. Trans. A, 2007, vol. 38A, pp. 1608-20.

3. H.S. Jeong, J.R. Cho, and H.C. Park: Key Eng. Mater., 2007, vols. 345-346, pp. 1429-32.

4. O.N. Senkov, D.W. Mahaffey, S.L. Semiatin, and C. Woodward: Metall. Mater. Trans. A, 2014, vol. 45A, pp. 5545-61.

5. M. Maalekian: Sci. Technol. Weld. Join., 2007, vol. 12, pp. 738-59.

6. M.M. Attallah and M. Preuss: in Welding and Joining of Aerospace Materials, M.C. Chaturvedi, ed., Woodhead Publishing, Oxford, 2012.

7. O.N. Senkov, D.W. Mahaffey, S.L. Semiatin, and C. Woodward: J. Mater. Eng. Perform., 2015, vol. 24, pp. 1173-84.

8. M. Preuss, P.J. Withers, and G.J. Baxter: Mater. Sci. Eng. A, 2006, vol. 437 , pp. $38-45$.
9. M. Preuss, J.Q. Da Fonseca, I. Kyriakoglou, P.J. Withers, and G.J. Baxter: Superalloys 2004, TMS, Warrendale, 2004, pp. 477-84.

10. A Chamanfar, M Jahazi, and J Cormier: Metall. Mater. Trans. A, 2015, vol. 46A, pp. 1639-69.

11. M.B. Mohammed, T.H. Hyde, C.J. Bennett, and E.J. Williams: ASME Turbo Expo 2009: Power for Land, Sea and Air, ASME, Orlando, 2009, pp. 829-37.

12. O.T. Midling and O. Grong: Acta Metall. Mater., 1994, vol. 42, pp. $1595-1609$

13. D.F. Wilcock and E.R. Booser: Bearing Design and Application, McGraw-Hill, New York, 1957.

14. F. Kreith and D.Y. Goswami: The CRC Handbook of Mechanical Engineering, CRC Press, Boca Raton, 2005, vol. 2.

15. B.S. Herbage, In Sixth Turbomachinery Symposium, M. P Boyce ed., Texas A\&M University Press, College Station, 1977, pp 33-38.

16. F.F. Wang, W.Y. Li, J.L. Li, and A. Vairis: Int. J. Adv. Manuf. Technol, 2014, vol. 71, pp. 1909-18.

17. L.W. Zhang, J.B. Pei, Q.Z. Zhang, C.D. Liu, W.H. Zhu, S. Qu, and J.H. Wang: Acta Metall. Sin. (English Letters), 2007, vol. 20, pp. $301-06$.

18. I. Wang, M. Preuss, P.J. Withers, G. Baxter, and P. Wilson: Metall. Mater. Trans. B, 2005, vol. 36B, pp. 513-23.

19. L.B. Yang, J.C. Gebelin, and R.C. Reed: Mater. Sci. Technol., 2011, vol. 27, pp. 1249-64.

20. J.S. Tiley, D.W. Mahaffey, O.N. Senkov, T. Alam, P Rojhirunsakool, T. Parthasarthy, and R. Banerjee: Mater. Sci. Eng. A, 2016, vol. 662, pp. 26-35. 